University of Tennessee Health Science Center UTHSC Digital Commons

\title{
An Analysis of the Differences in Preemptive Kidney Transplantation Between Blacks and Whites
}

Kennard D. Brown

University of Tennessee Health Science Center

Follow this and additional works at: https://dc.uthsc.edu/dissertations

Part of the Health and Medical Administration Commons

\section{Recommended Citation}

Brown, Kennard D. , "An Analysis of the Differences in Preemptive Kidney Transplantation Between Blacks and Whites" (2008). Theses and Dissertations (ETD). Paper 32. http://dx.doi.org/10.21007/ etd.cghs.2008.0036. 


\title{
An Analysis of the Differences in Preemptive Kidney Transplantation Between Blacks and Whites
}

\begin{abstract}
Background. This cohort study investigates whether there are inequities in the allocation of cadaver kidneys for preemptive kidney transplants (PKT) between blacks and whites.

Methods. This analysis uses descriptive statistics and univariate and multivariate analyses to identify factors associated with the determination of whether a patient receives a PKT or a conventional, post dialysis kidney transplant. The sample includes patients identified by the Centers for Medicare and Medicaid Services (CMS) as having end stage renal disease (ESRD), >19 years of age, either black or white, and receiving either a PKT ( $0-<6$ months $>$ dialysis) or conventional transplant between January 1 , 2000 and December 31, $2003(n=10,067)$ from any of the 11 organ procurement regions in the United States.

Results. Whites were more likely to receive a PKT $(p<0.05)$. Females were $23 \%$ more likely to receive a preemptive kidney transplant as males. Those without hypertension as the primary cause of ESRD were more than 3 times more likely to receive a PKT. Those without diabetes as the primary cause of ESRD were as than 2 times more likely to receive a PKT. Those without glomerulonephritis as the primary cause of ESRD were more than 2 times as likely to receive a PKT. Interestingly, this research shows that the leading causes of ESRD in blacks and whites who received PKTs was diabetes, $22 \%$ and $31 \%$ respectively. Black conventional transplant recipients had higher rates of hypertension and diabetes than did black PKT recipients overall. White conventional kidney transplant recipients had the highest rates of diabetes (39.19\%) of all groups. Of all PKT recipients, blacks received $10.76 \%$ compared with $89.24 \%$ received by whites. The mean age for blacks receiving PKTs was 48.4 years of age compared with 47 years of age for black conventional kidney transplant recipients. The mean age for whites, both PKT and conventional transplant recipients was approximately 49 years of age. Higher percentages of PKTs took place in the northeastern and southeastern regions (UNOS regions 2 and 3) of the United States. The majority of PKT recipients, both blacks and whites, received their donor organs from whites. Blacks received $69.42 \%$ white donor, organs compared with $77.61 \%$ received by whites. Blacks did receive $17.43 \%$ of their donor organs from blacks, with whites receiving approximately $6 \%$ of their organs from blacks. For those receiving PKTs during the study period, $86 \%$ of whites and $81 \%$ of blacks were still alive with functioning grafts at the conclusion of the study period. Medicare A and B as the primary insurance and those who had Medicare as a secondary payer each did reflect statistical significance as indicators of being less likely than patients insured otherwise.
\end{abstract}

Conclusion. From this analysis it is concluded that a disparity exists in the allocation of PKTs between blacks and whites. These results indicate that blacks are less likely to receive a PKT than their white ESRD counterparts, females are more likely to receive a preemptive kidney transplant than males, and that both males and females are more likely to receive a PKT if they do not have a diagnosis as the primary cause of their ESRD of hypertension, diabetes and/or glomerulonephritis. These results suggest that there may be remediable inequities in the current system relating to the policies of UNOS and that PKTs can be allocated in a more equitable manner.

Document Type

Dissertation

Degree Name

Doctor of Philosophy (PhD) 


\section{Program}

Health Science Administration

Research Advisor

Shelly White-Means, Ph.D.

\section{Keywords}

kidney transplant, preemptive transplant, renal transplant, health disparities

\section{Subject Categories}

Health and Medical Administration | Medicine and Health Sciences 


\title{
AN ANALYSIS OF THE DIFFERENCES IN PREEMPTIVE KIDNEY TRANSPLANTATION BETWEEN BLACKS AND WHITES
}

\author{
A Dissertation \\ Presented for \\ The Graduate Studies Council \\ The University of Tennessee \\ Health Science Center
}

\begin{abstract}
In Partial Fulfillment
Of the Requirements for the Degree

Doctor of Philosophy

From The University of Tennessee
\end{abstract}

By

Kennard D. Brown, M.P.A., J.D.

May 2008 
Copyright (C) 2008 Kennard Dudley Brown All rights reserved 


\section{DEDICATION}

This research is dedicated to my wife, Cynthia, my sons Kenny and Devin, and my

mother, Pinky who have sacrificed more than I could have asked over the years this work has taken form. To my late grandmother, Katie Robinson, who could not read and write but taught me the importance of my doing so. 


\section{ACKNOWLEDGEMENTS}

I would like to acknowledge the members of my dissertation committee, Drs. Mona Wicks, Donna Hathaway, Junling Wang, Rob Nolly and in particular my committee chair and dear friends, Dr. Shelley White-Means and Dr. Betsy Tolley and a host of other dear

friends, too many to mention, without whom this would not have been possible. I also thank and offer a special expression of gratitude to Shirley Hancock, who provided editorial support. 


\begin{abstract}
Background. This cohort study investigates whether there are inequities in the allocation of cadaver kidneys for preemptive kidney transplants (PKT) between blacks and whites.
\end{abstract}

Methods. This analysis uses descriptive statistics and univariate and multivariate analyses to identify factors associated with the determination of whether a patient receives a PKT or a conventional, post dialysis kidney transplant. The sample includes patients identified by the Centers for Medicare and Medicaid Services (CMS) as having end stage renal disease (ESRD), >19 years of age, either black or white, and receiving either a PKT (0$<6$ months dialysis) or conventional transplant between January 1, 2000 and December 31, $2003(n=10,067)$ from any of the 11 organ procurement regions in the United States.

Results. Whites were more likely to receive a PKT $(\mathrm{p}<0.05)$. Females were $23 \%$ more likely to receive a preemptive kidney transplant as males. Those without hypertension as the primary cause of ESRD were more than 3 times more likely to receive a PKT. Those without diabetes as the primary cause of ESRD were as than 2 times more likely to receive a PKT. Those without glomerulonephritis as the primary cause of ESRD were more than 2 times as likely to receive a PKT. Interestingly, this research shows that the leading causes of ESRD in blacks and whites who received PKTs was diabetes, $22 \%$ and $31 \%$ respectively. Black conventional transplant recipients had higher rates of hypertension and diabetes than did black PKT recipients overall. White conventional kidney transplant recipients had the highest rates of diabetes (39.19\%) of all groups. Of all PKT recipients, blacks received $10.76 \%$ compared with $89.24 \%$ received by whites. The mean age for blacks receiving PKTs 
was 48.4 years of age compared with 47 years of age for black conventional kidney transplant recipients. The mean age for whites, both PKT and conventional transplant recipients was approximately 49 years of age. Higher percentages of PKTs took place in the northeastern and southeastern regions (UNOS regions 2 and 3) of the United States. The majority of PKT recipients, both blacks and whites, received their donor organs from whites. Blacks received $69.42 \%$ white donor, organs compared with $77.61 \%$ received by whites. Blacks did receive $17.43 \%$ of their donor organs from blacks, with whites receiving approximately $6 \%$ of their organs from blacks. For those receiving PKTs during the study period, $86 \%$ of whites and $81 \%$ of blacks were still alive with functioning grafts at the conclusion of the study period. Medicare A and B as the primary insurance and those who had Medicare as a secondary payer each did reflect statistical significance as indicators of being less likely than patients insured otherwise.

Conclusion. From this analysis it is concluded that a disparity exists in the allocation of PKTs between blacks and whites. These results indicate that blacks are less likely to receive a PKT than their white ESRD counterparts, females are more likely to receive a preemptive kidney transplant than males, and that both males and females are more likely to receive a PKT if they do not have a diagnosis as the primary cause of their ESRD of hypertension, diabetes and/or glomerulonephritis. These results suggest that there may be remediable inequities in the current system relating to the policies of UNOS and that PKTs can be allocated in a more equitable manner. 


\section{TABLE OF CONTENTS}

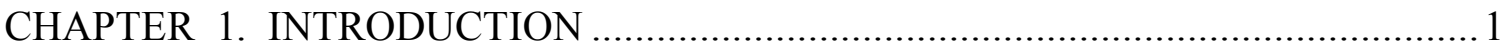

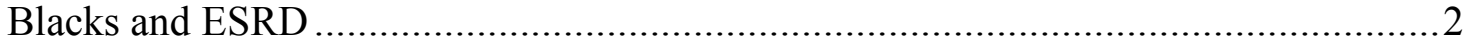

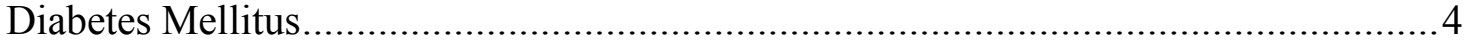

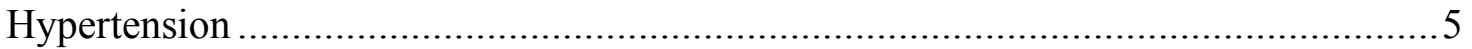

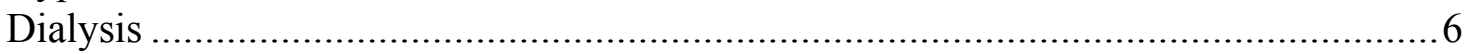

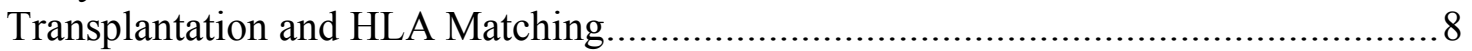

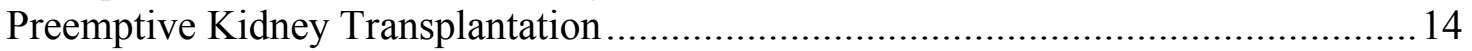

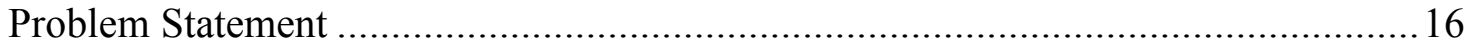

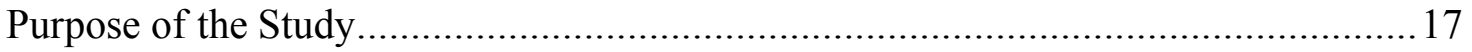

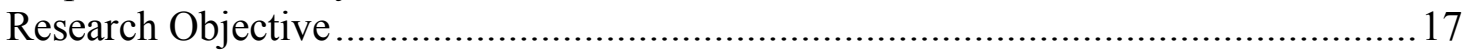

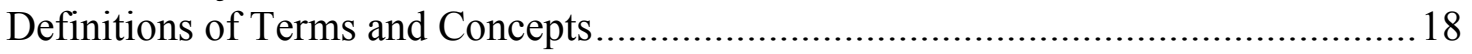

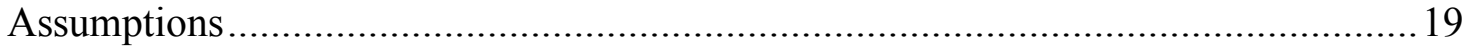

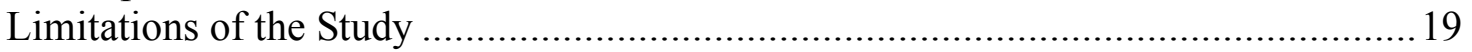

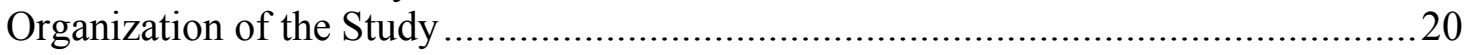

CHAPTER 2. REVIEW OF THE LITERATURE ………..........................................2

Racial Differences in Access to Kidney Transplantation .........................................21

Preemptive Kidney Transplantation ........................................................................ 31

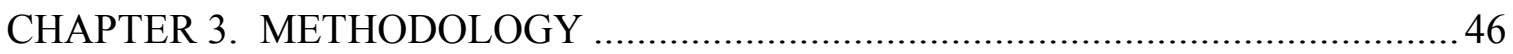

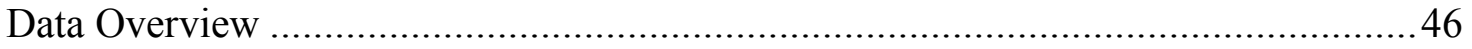

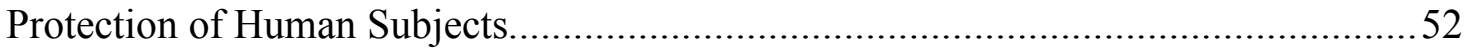

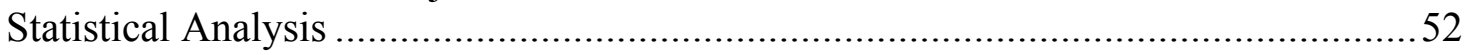

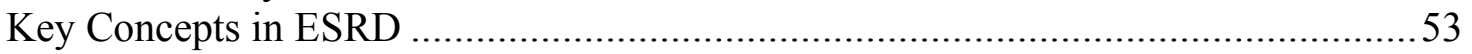

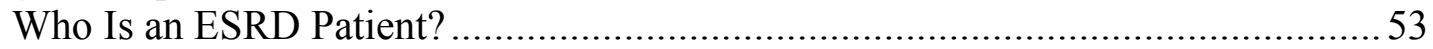

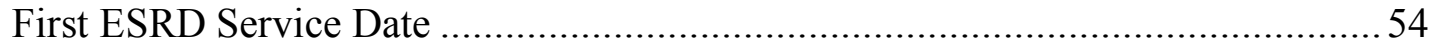

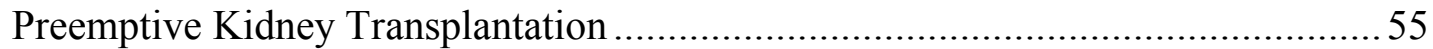

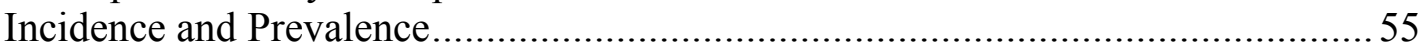

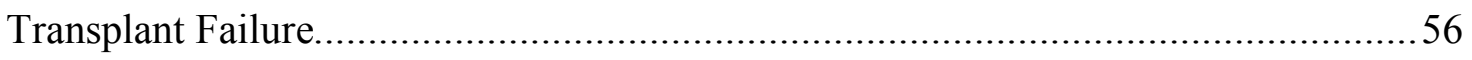

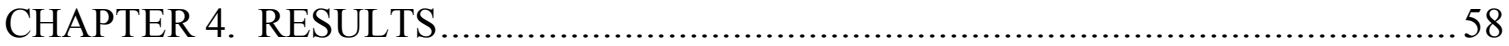

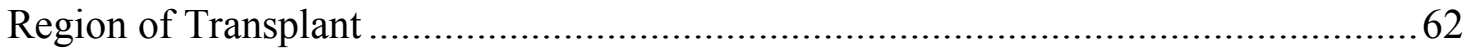

Characteristics of Preemptive and Conventional Transplant Recipients......................66

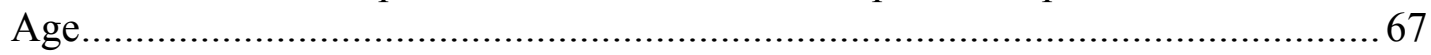

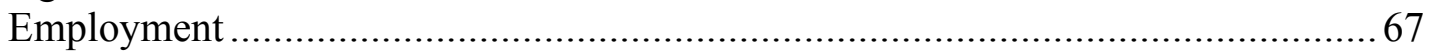

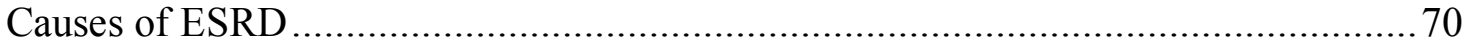

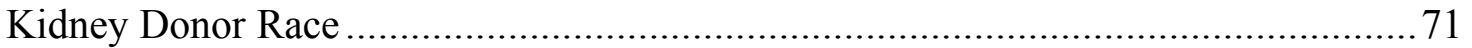

Patient Outcomes for PKT and Conventional Kidney Transplant Recipients..............73

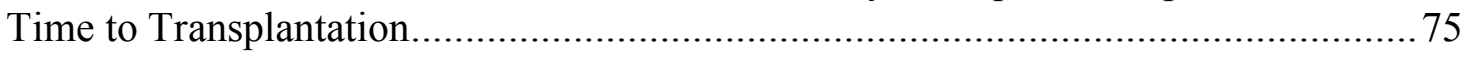

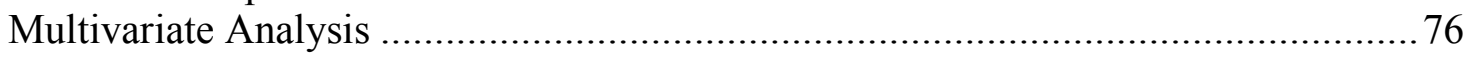




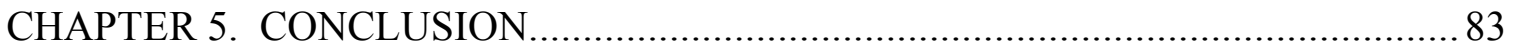

Disparities in PKT, UNOS, and the Health Policy Implications ...............................8 88

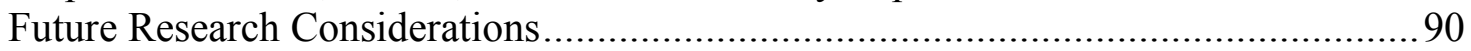

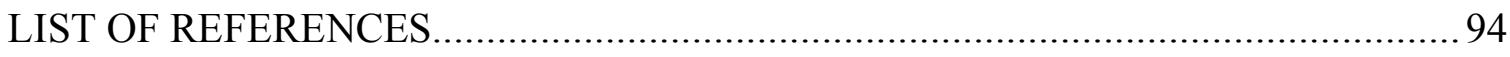

VITA 


\section{LIST OF TABLES}

Table 1-1. Former renal allocation point system for allocating cadaver kidneys in the United States ……......................................................................... 10

Table 1-2. Current United Network for Organ Sharing Organ Allocation Point System for allocating cadaver kidneys in the United States...................... 13

Table 4-1. Year of first ESRD service for 10,067 patients included in the current cohort.

Table 4-2. Year of transplant, frequency, percentage and cumulative frequency and percentage by year

Table 4-3. Frequency and percentage of PKT and conventional transplant recipients by region.....

Table 4-4. Frequency and percentage of PKT and conventional kidney transplant recipients by region and by race

Table 4-5. Frequency of PKT and conventional transplants occurring between January 1, 2000 and December 31, 2003 among patients who developed ESRD during the same time period, according to gender and race.

Table 4-6. Mean age in years of patients by race receiving either a PKT or conventional kidney transplant between January 1, 2000 and December 31, 2003 .

Table 4-7. Age category at first ESRD service and kidney transplant frequency included in the current cohort.....

Table 4-8. Employment status in percentages of PKT and conventional transplant recipients by race

Table 4-9. Primary disease causes of ESRD in frequency and percentages of PKT and conventional kidney transplant recipient, by race ............................. 72

Table 4-10. Kidney donor race in frequency and percentages of PKT and conventional kidney only transplant recipients.

Table 4-11. Percentages and frequencies for various outcomes for patients receiving a PKT or conventional transplant ........................................... 74

Table 4-12. Racial disparity in elapsed time from first service for dialysis and transplantation.... .76

Table 4-13. Recipient characteristics associated with preemptive kidney transplantation.

Table 4-14. Medicare A and B only recipient characteristics associated with preemptive kidney transplantation....

Table 4-15. Recipient characteristics associated with a preemptive kidney transplantation with employment and Medicare A and B as primary payer and/or Medicare as a secondary payer included in the model. 


\section{LIST OF FIGURES}

Figure 1-1. Incidence rates of ESRD due to diabetes, hypertension, and other renal disease according to ethnicity.

Figure 2-1. Cumulative incidence of wait listing for black and white pediatric patients after first dialysis for ESRD.................................................29

Figure 3-1. Structure of the USRDS database. ................................................... 51

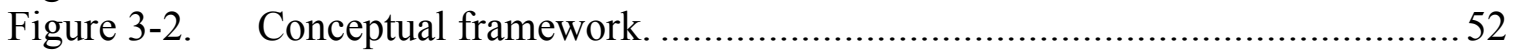

Figure 4-1. Flow chart of patients from entry into Center for Medicare Services System via standard analytical files through either PKT or conventional cadaver kidney transplant 60

Figure 5-1. Differences, disparities, and discrimination: Populations with equal access to health care. 85 


\section{LIST OF ABBREVIATIONS}

CAPD continuous ambulatory peritoneal dialysis

CDC. Centers for Disease Control

CKD. chronic kidney disease

CMS Center for Medicare Services

EMR electronic medical record

ESRD .end-stage renal disease

GFR glomerular filtration rate HCFA Health Care Financing Administration

HLA. human leukocyte antigen

NKF National Kidney Foundation

OLTP On-Line Transaction Processing OPTN Organ Procurement Transplant Network

PKT preemptive kidney transplantation

PMMIS Program Management and Medical Information System REBUS Renal Beneficiary and Utilization System

RMIS Renal Management Information System

UNOS United Network for Organ Sharing USRDS United States Renal Data System 


\section{CHAPTER 1. INTRODUCTION}

The first successful kidney transplant performed by Dr. Joseph Murray took place over 50 years ago. Subsequently, the field of kidney transplantation has continued to evolve, and long-term survival following transplantation has surpassed survival on dialysis for all races (Wolf, et al., 1999). Renal transplantation reduces mortality, improves quality of life, and is less costly than dialysis (Kasiske, et al., 2000). The benefits of kidney transplantation have been shown regardless of recipient sex, race, age, or cause of end stage renal disease (ESRD) (Wolf et al., 1999). The benefits of preemptive kidney transplantation (PKT) have shown it to be the optimal strategy to benefit patients requiring renal replacement therapy (Wolf, et al., 1999). Although both blacks and whites have benefited from these advances, it remains unfortunate that use of these life-prolonging modalities is not equivalent among all races; also equivalent success eludes blacks who are disadvantaged in gaining kidney transplants. Constituting almost half of those waiting for a renal transplant, blacks receive less than $28 \%$ of all cadaver-donor kidneys each year and an even smaller percentage of PKT before the initiation of maintenance dialysis (Young \& Kew, 2005).

Kidney transplantation has historically taken place after a variable period of dialysis therapy. The optimal timing of kidney transplantation and the question of whether one receives a transplant preemptively or begins routine dialysis maintenance is the subject of much controversy (Katz et al., 1991; Roake et al., 1996). The debate regarding preemptive kidney transplantation (PKT) is compounded by the fact that first of all it takes place contrary to the policies outlined by the United Network for Organ Sharing and secondly it is hypothesized by this research that since blacks have not historically enjoyed the benefits of 
conventional renal transplantation to the same degree as their white counterparts (Norris \& Agodoa, 2005) they most certainly do not enjoy the relative frequency of PKT as do their white counterparts. Because blacks are much less likely than whites to be referred for evaluation at a transplant center, to be placed on a waiting list, or to receive traditional postdialysis transplants (Ayanian et al., 1999), it logically follows that their use of PKT would be limited as well. Given the disparities blacks have experienced with renal replacement and the benefits attributed to PKT, the question remains whether blacks will fare any better in the PKT arena when compared with their white counterparts. The current analysis of data obtained from the United Network for Organ Sharing (UNOS) and United States Renal Data system (USRDS) examined the characteristics of patients who received either PKT or conventional transplants, the effect of PKT or conventional transplants on outcomes, whether the effects on outcomes were similar in both PKT and conventional transplant patients and whether these effects were independent of recipients race and/or other factors.

\section{BLACKS AND ESRD}

To create a context for the current study's examination of the disparity in PKT, brief overviews are provided of the end stage renal disease (ESRD) problem and how blacks now have such a significant need for transplantation. Chronic kidney disease (CKD) occurs when the kidneys begin to fail in their ability to excrete wastes, concentrate urine, and regulate electrolytes. The National Kidney Foundation (NKF) estimates that 20 million Americans have CKD, and at least 20 million others are at increased risk to develop CKD. End stage renal disease (ESRD) occurs when the kidneys are no longer able to function at a level necessary for day-to- day life, which is usually when kidney function drops below $10 \%$ of 
normal functioning capacity. During the last decade, the number of ESRD patients in the United States grew at an exponential rate-doubling from 201,454 in 1991 to 406,081 in 2001 (Norris \& Agodoa, 2005). There was a 4.2\% increase in the ESRD population between 2000 and 2001 (Szczech \& Lazar, 2004). There are projections that the ESRD population will increase to 700,000 by 2010 and to more than 2 million people by 2030 (Szczech \& Lazar, 2004).

A review of recent data indicates that ESRD occurs nearly four times more frequently among blacks than their white counterparts, and continues to represent one of the most dramatic examples of health disparities in our nation (Norris \& Agodoa, 2002). The black population consistently has suffered from a greater than 3.5-fold higher rate of treated ESRD than the white population. The United States Renal Data System (USRDS) annual report from 2004 noted that blacks in the United States continued to have a disproportionately greater incidence and prevalence rate of ESRD (Fig. 1-1) (Agodoa, 2003). The overall adjusted incidence rate of new black ESRD patients in 2003 was 998 per million population, compared with 334 per million for whites. This represented a quadrupling of the overall incidence of ESRD since 1980 (USRDS, 2003).

Correspondingly, the ESRD program has a significant over-representation of blacks. Although some factors contributing to these alarming rates of ESRD among blacks have been identified, the exact reasons why these disparities exist have yet to be fully elucidated. Despite concerted efforts to better understand the causative factors that precipitate renal disease in blacks, ESRD in the U.S. is likely to remain disproportionately higher in blacks. As a result, blacks will continue to disproportionately populate dialysis centers and transplant center waiting lists. 


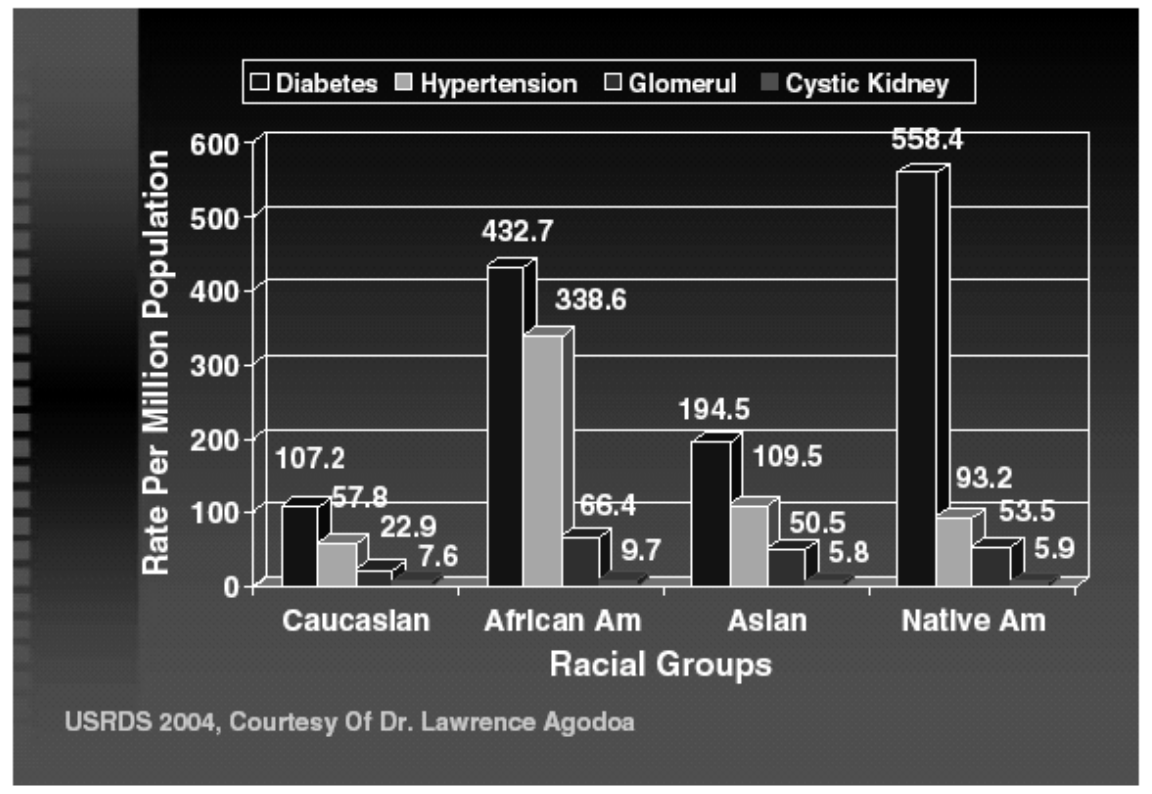

Figure 1-1. Incidence rates of ESRD due to diabetes, hypertension, and other renal disease according to ethnicity.

Source: Agodoa L. Lessons from chronic renal diseases in African Americans: Treatment implications. Ethn Dis 2003;13:S120. Reprinted with permission.

\section{DIABETES MELLITUS}

Approximately $70 \%$ of all new adult ESRD cases in the United States are attributable to diabetes and hypertension. Diabetes is the leading cause of ESRD, with glomerulonephritis and cystic kidney diseases constituting about $10 \%$ of cases (see Fig. 1-1) (Agodoa, 2003). The prevalence of diabetes in black men is nearly 50\% greater than in white men, and black women are $100 \%$ more likely to have diabetes than white women (Crook et al., 2001). An estimated (NHANES III, 1988-1994) 8\% of adults in the United States have type 2 diabetes mellitus (Harris, 1998), and the incidence of this disease is increasing (USRDS, 2003). The number of cases of diabetes mellitus, and consequently diabetic nephropathy, is also rising progressively worldwide (King, 1998). Diabetic nephropathy 
occurs in about one third of patients with diabetes mellitus and is the most common cause of ESRD in most industrialized nations_-accounting for nearly half of new ESRD cases (USRDS, 2003). Relative to whites, the incidence of diabetes mellitus is 2.3 times higher in blacks than whites (USRDS, 2003).

Krop et al. (1999) noted that blacks with diabetes mellitus had early renal function decline three times that of whites. More than $80 \%$ of this disparity has been attributed to lower socioeconomic status, suboptimal health behaviors, and suboptimal control of blood glucose level and blood pressure. This trend is likely to continue because the incidence of type 2 diabetes mellitus is fueled by the increasing prevalence of obesity among blacks.

\section{HYPERTENSION}

The second most common cause of ESRD is hypertension. The prevalence of hypertension among blacks in the United States has increased substantially and is the highest in the world (Coresh et al., 2001). Among young blacks aged 20 to 44 years, the incidence of hypertension is 20 times higher than that of whites (USRDS 2001, Annual Report). The age adjusted prevalence of hypertension in blacks is $32.4 \%$, which is nearly $40 \%$ higher than whites (23\%) (Burt et al., 1995). The pattern of hypertensive ESRD is unique among blacks; it has remained a leading cause of ESRD for all ages, from the pediatric group — which is uncommon in other racial/ethnic groups - through the geriatric black population (Agodoa, 2003). Among several theories that have been proposed to explain the significant hypertensive rates among blacks is the possibility that environmental and genetic factors (excess salt intake superimposed on a genetic predisposition to salt retention) may lead to low-renin hypertension (Warnock, 2000). Blacks may have a predisposition to the 
deleterious effects of hypertension on renal function, even if blood pressures are well controlled (Hall et al., 1997). Added to these physiologic variables are the socioeconomic and educational disadvantages often encountered by blacks, many of whom never received care for their hypertension before developing irreversible kidney failure (Geiger, 1996). Hypertension is a major contributing factor in the increased prevalence of ESRD seen in the black population, leading to dialysis or transplantation (UNOS 1999, Annual Report). In sum, there are proportionately more blacks entering the ESRD network; yet, as a group, they are significantly under-represented in the population receiving renal transplants (Young \& Kew, 2005).

Although diabetes, hypertension, and some of the other factors contributing to the alarming rates of ESRD among blacks have been identified, the reasons for the disparities in transplantation rates between blacks and whites have yet to be fully explained. For the time being it appears that ESRD is likely to remain disproportionately higher in blacks and, therefore, result in many more blacks remaining on dialysis and awaiting kidney transplants.

\section{DIALYSIS}

A disproportionate number of black patients receive hemodialysis as the treatment modality for renal replacement therapy. Data from the USRDS in 1999 revealed that black patients had the highest incidence of hemodialysis among all racial or ethnic populations (Gadegbeku, Freeman \& Lawrence, 2002). Although dialysis is life prolonging, extended periods on dialysis are detrimental to subsequent renal allograft survival. Furthermore, late or emergency referral to dialysis, which is associated with three-fold higher mortality and morbidity rates, longer and more expensive hospital stays (Roubicek, Brunet \& Huiart, 
2000), is more likely to occur in blacks than whites. Lower levels of kidney function at initiation of dialysis appear to a greater extent in blacks than in other racial groups (Kausz et al., 2000). Even when dialysis is undertaken, despite the clear guidelines for hemodialysis dose and monitoring, the prescribed dose is more likely to be suboptimal in black hemodialysis patients (Owen et al., 1998).

Because of the increasing incidence and prevalence of ESRD there is an ever increasing shortage of kidneys for transplantation. As a result of this shortage combined with additional pathophysiological factors, blacks are less likely to receive a transplanted kidney than are their white counterparts. This diminished likelihood of receiving a transplant has been linked to nephrologists' delaying referral of blacks for transplantation and the diminished likelihood of their being placed on the UNOS waiting list (Roizon-Solomon \& Burrows, 1999). As a result, most blacks with ESRD receive hemodialysis to perform the work of their diseased kidneys.

Despite the hefty representation of blacks on hemodialysis, the annual death rate was 181/100 patient years, lower than the 284.7/1000 patient years for whites (USRDS, 2002). The lower rate has been attributed to blacks fairing better than whites on dialysis; however, this conclusion may be incorrect. Because blacks on hemodialysis tend to be younger, a possible explanation for this difference in death rats is that blacks on dialysis are healthier than whites on dialysis and are better able to withstand dialysis treatment. In 2002, 54\% of patients on dialysis under age 50 years old were black; this percentage decreased to $39 \%$ for those over age 50 years (USRDS, 2002). It follows that blacks who are suitable candidates for renal transplantation are not being transplanted but are waiting on dialysis. Conversely, the older, less healthy, and more likely un-transplantable patients (older whites with co- 
morbidities) are dying on dialysis and possibly creating the false impression that death rates are higher. Between 1997 and 2000, 49,963 cadaver donor renal transplants took place in the United States (Young \& Kew, 2005). Of these allograft, 35,532 (71\%) were transplanted into whites, whereas $11,667(23 \%)$ went to blacks. Therefore, it was surmised that the decrease in the proportion of whites in the prevalent population was mainly due to their referral for renal transplantation and not patient death (Agodoa, 2003).

\section{TRANSPLANTATION AND HLA MATCHING}

On December 23, 1954, the first successful human organ transplant was performed. A kidney was transplanted from a living donor who was an identical twin of the recipient. Because immunosuppressive therapy had not evolved to its current state, there was no consideration given to the use of cadaver organs. The burden for finding a suitable living donor rested with those in need of organs. There was no waiting list and no apparent shortage of organs (Barnett \& Kaserman, 2000). Not long after the first successful transplant, improved tissue matching made transplantation of cadaver kidneys possible. In 1972 the ESRD program, which was administered by the Social Security Administration, extended federal insurance coverage to kidney transplantation and dramatically increased the demand for cadaver organs. This change led to a shift in kidney procurement policy, from focusing exclusively upon living related donors to the procurement of cadaver organs from unrelated donors. The kidney transplant waiting list managed by health professionals at local transplant centers, began to form in the late 1970s putting pressure on scientists to find ways to alleviate the shortage of transplantable kidneys. Given the predominantly white donor population in the United States, black ESRD patients were at an obvious disadvantage in 
their chances of receiving a suitable kidney. This situation was and continues to be compounded by lower levels of organ donation among blacks due, at least in part, to many cultural factors (Epstein et al., 2000).

Research shows that blacks are less likely than white patients to be considered appropriate candidates for transplantation (9\% versus $21 \%$, respectively) and that blacks continue to be more likely to have an incomplete transplant workup (47\% versus $39 \%$ ) (Epstein et al., 2000). The most common reasons offered for blacks being considered inappropriate for transplantation were a body mass index over 35 , presence of an active infection and presence of extra-renal, non-cardiac co-morbidities. Even after candidacy is established among patients considered suitable for a transplant, blacks still remain at a disadvantage and are still less likely than whites to actually receive a transplant (17\% vs. 52\%, respectively) (Epstein et al., 2000).

The United Network for Organ Sharing (UNOS) allocation policy mandates ABO blood type identity. Although this is a necessary policy, black candidates, by nature of the donor pool (predominantly white), are disadvantaged by a predilection for $\mathrm{ABO}$ blood types associated with longer waits (Epstein et al., 2000). Another important facet in determining who receives a kidney transplant is the relative weight given the anti-major histocompatibility complex (MHC) matching in the former UNOS allocation algorithm (Table 1-1). Wait-listed transplant candidates accumulate " points." When a kidney becomes available, the medically suitable candidate with the most points is designated to receive the organ. Based on the assumption that similarity in MHC antigen expression (i.e., matching) between donor and recipient optimizes outcomes, matching was the predominant variable determining allocation of deceased-donor kidneys (Norman, 1995). The primary 
Table 1-1. Former renal allocation point system for allocating cadaver kidneys in the United States.

\begin{tabular}{lc}
\hline Criterion & $\begin{array}{c}\text { Points } \\
\text { Awarded }\end{array}$ \\
\hline Zero antigen mismatch & mandatory share \\
MHC mismatches & 7 \\
0 BDR & 5 \\
1 BDR & 2 \\
2 BDR & \\
Presensitization & 4 \\
Panel reactive antibody $\geq 80 \%$ & \\
Waiting time & 1 \\
Longest wait (then fractional) & 1 \\
Each year on list & \\
Age & 4 \\
$<11$ y & 3 \\
$11-18$ y & \\
\hline
\end{tabular}

Source: Young, C.J., Kew C. Health disparities in transplantation: focus on the complexity and challenge of renal transplantation in African Americans. Med Clin N Am 2005; 89:100331 . 
benefit of this allocation algorithm was unintentionally conferred on the predominantly white recipients of completely matched grafts, with marginal impact on outcomes across other match grades, especially among black recipients. This trend was recognized over a decade ago with few inter-racial transplants occurring with greater than three (of six) matched MHC alleles (Lazda, 1992).

Takemoto et al. (2000) reviewed the UNOS database from 1987 to September 1999 under the UNOS allocation algorithm to determine the efficacy of sharing HLA matched kidneys. Although blacks benefited from this sharing, they received only $8 \%$ of the 7,614 matched kidneys. Conversely, $30 \%$ of mismatched kidneys went to blacks, approximating the frequency with which blacks appeared on the wait list (Scantlebury et al., 1998). Even the proponents of the former allocation system conceded that racial disparity existed (Takemoto et al., 2000). This fact was made more unacceptable when improved immunosuppressive medications reduced the impact of matching on allograft survival (Cecka, 1999). The core of the former point system was implemented in the 1980s when demonstrable incremental benefit of improved HLA compatibility between donor and recipient was evident. Now, at least two groups of investigators estimate that the overall benefit of improved HLA compatibility between donor and recipient is relatively small, improving graft survival by only 1\%-2\% (Held et al., 1994; Feldman et al., 1997).

In addition, early reports documented no statistical benefit of matching among blacks, a finding attributed to the difficulty of obtaining enough good matches in this population for meaningful analysis (Takemoto et al., 1994). Current data indicate a benefit for blacks of $5 \%-6 \%$ (in graft survival at 3 years) in the few patients able to receive completely matched grafts, and improvement in allograft half-life from 5.4 to 8.4 years (the latter still being less 
than the years expected for white recipients of mismatched kidneys) (Scantlebury et al., 1998).

A new UNOS renal allocation scheme was implemented in May 2003 to address discrepancies in kidney allocation that result from a heterogeneous HLA donor and recipient population (Table 1-2). Implementation of this new scheme has been an important step in rectifying the disparity in allocation of kidney transplants among black and white transplant candidates. Inasmuch as the former UNOS algorithm perpetuated ethnic disparities, major changes have occurred while preserving mandatory sharing of phenotypically identical (completely matched) kidneys because it improves transplant outcomes and, despite identifiable adverse impact on access for blacks, removes relatively few organs from the overall pool (Young \& Kew, 2005).

Beyond phenotypic identity, allocation of points for "partial" matching was determined indefensible. A 1995 analysis confirmed that "matching points" were accumulated disproportionately by whites and awarded for match quality that produced outcomes no better (two mismatches) or worse (three mismatches) than the national average (Meier-Kriesche, et al., 2000). In response, the algorithm was modified to its current form. The impact of these modifications on access for blacks is being assessed (Young \& Kew, 2005). A recent regional study involving the New England Organ Bank documented that elimination of points for partial matching indeed improved access for blacks without compromising outcomes (Delmonico, et al., 1999). Other modifications are possible.

Currently, UNOS allows local variances based on the concept of acceptable mismatches that preserve the benefits of matching while offering more equitable allocation. Although some investigators remain unenthusiastic about the potential benefit of such an 
Table 1-2. Current United Network for Organ Sharing Organ Allocation Point System for allocating cadaver kidneys in the United States.

\begin{tabular}{lc}
\hline Criterion & $\begin{array}{c}\text { Points } \\
\text { Awarded }\end{array}$ \\
\hline Zero antigen mismatch & mandatory share \\
MHC mismatches & 2 \\
0 BDR & 1 \\
1 BDR & 0 \\
2 BDR & \\
Presensitization & 4 \\
Panel reactive antibody $\geq 80 \%$ & \\
Waiting time & 1 \\
Longest wait (then fractional) & 1 \\
Each year on list & \\
Age & 4 \\
$<11$ y & 3 \\
$11-18$ y & \\
\hline
\end{tabular}

Source: Young, C.J., Kew C. Health disparities in transplantation: focus on the complexity and challenge of renal transplantation in African Americans. Med Clin N Am 2005; 89:100331 . 
approach, prospective evaluation of its merits is pending. Alternatively, in light of increasing recognition of the influence of non-immunologic factors (particularly early graft function and donor age) on long-term survival, it may be time to formulate a completely new paradigm for organ allocation, especially in light of the success that has been achieved with PKT.

\section{PREEMPTIVE KIDNEY TRANSPLANTATION}

Transplantation is recognized as preemptive if it takes place before the initiation of chronic maintenance dialysis. PKT is an appealing option for patients who are approaching end stage renal failure but who have not yet progressed to dialysis. Theoretical advantages include avoiding the inconvenience of frequent hemodialysis sessions or frequent exchanges of peritoneal fluid, the significant morbidity associated with multiple access procedures, the risk related to repeated blood transfusions, and the complications of prolonged uremia (Papalois et al., 2000). In addition, preemptive transplantation eliminates the substantial cost of dialysis.

In the past there was some concern that this strategy might be associated with an increased risk of graft loss from rejection, because these patients would not experience the immunosuppressive effects of uremia. In addition, it has been suggested that compliance after transplantation might be reduced if the patients had not experienced dialysis as the first modality of renal replacement therapy. However, a number of recent reports indicate that PKT gives the clear benefits of not only avoidance of morbidity associated with dialysis and reduced cost of renal replacement therapy but also significant increases in both patient and graft survival (Roake et al., 1996). PKT decreased the rate of allograft failure by $25 \%$ for cadaver donor transplants (Kasiske et al., 2002). The basis for the allograft survival 
advantage in preemptive recipients is unclear. Possibilities include a lead time bias due to the earlier transplantation of patients with preserved native kidney function, less rapid loss of kidney function after transplantation, or the longer patient survival of PKT recipients.

Despite the success of PKT in reducing the rate of allograft failure, it accounts for only $7 \%$ to $8 \%$ of cadaver donor transplants (Kasiske et al., 2002).

While it is hypothesized that the lower rate of PKT among cadaver donor transplants likely resulted from the prolonged duration of time waiting for a cadaver donor, this hypothesis is not supported by the literature. Previous studies using national data from the UNOS transplant registry have associated socioeconomic characteristics with rates of placement on the cadaver waiting list (Kasiske et al., 1998) and with the likelihood of receiving a cadaver renal transplant before the initiation of dialysis (Kasiske et al., 2002). Although these results have been informative, analysis of the UNOS registry does not allow for determination of the factors that affect the decision and timing of either PKT or placement on the waiting list.

Other studies have examined data exclusively from patients already on dialysis and, therefore, were not designed to address reasons associated with transplant evaluation before dialysis initiation (Alexander \& Sehgal, 1998; Ayanian et al., 1999; Winkelmayer et al., 2002). The factors that influence the decision to designate patients for PKT or dialysis are not well understood. Given the importance of the timing of PKT, the current study was performed to understand the factors that contribute to preemptive versus non-preemptive transplantation among persons who experienced renal failure and received a cadaver kidney transplant during a five year period from 2000 through 2003. 


\section{PROBLEM STATEMENT}

Dialysis has long been the established initial choice of therapeutic intervention for patients with ESRD. However, not only is dialysis associated with significant morbidity and a greater mortality than transplantation, but it is also expensive. Because of a clear survival benefit associated with renal transplantation, it has now become generally regarded as the preferred treatment option for ESRD. Kidney transplant recipients have been shown to live longer, have a higher quality of life, and consume fewer health care resources compared with patients on dialysis (Eggers, 1995; Wolfe et al., 1999; Winkelmayer et al., 2002). Kidney transplantation typically takes place after a period of dialysis. Recently, transplantation before initiation of dialysis has been advocated because the morbidity and cost of putting in a stint for dialysis access are avoided. PKT has been associated with an allograft survival advantage compared with transplantation after initiation of dialysis (Kasiske et al., 2002).

Ethnic disparities in access to renal transplantation are long standing and may be increasing (Callender, 1991). The incidence of ESRD in blacks is 4 times greater than that in whites, but blacks remain less likely than whites to be referred for or undergo traditional post-dialysis renal transplantation (Young \& Gaston, 2002). Eggers noted that blacks with ESRD have limited access to transplantation relative to whites (Eggers, 1988). Blacks receive only $25 \%$ of cadaver kidneys and have a median waiting time for a cadaver kidney that is twice as long as that of whites (UNOS 1999 Annual Report). Black ESRD patients, once fully informed of their options, prefer transplantation over dialysis as often as whites but are significantly less likely to proceed rapidly to transplantation (Young \& Gaston, 2002). Broad opinion is that blacks are being referred at a lesser rate than whites for traditional post-dialysis transplants (Young \& Gaston, 2002) and a hypothesis of this 
research is that they are being referred at a lesser rate for PKT as well. The observation that whites are more likely to be placed on the cadaver waiting list before dialysis initiation and receive a PKT suggest that there is some systemic bias in determining who receives and does not receive PKT (Kasiske et al., 1998; Kasiske et al., 2002). The focus of this research was to attempt to determine if blacks are being afforded PKT at a rate equal to that of whites and, if not, to determine if there are objective variables that may account for the difference, such as differences in comorbidities or insurance coverage.

\section{PURPOSE OF THE STUDY}

The purpose of this research was to determine whether there are inequities in the allocation of cadaver kidneys for preemptive kidney transplants (PKT) between blacks and whites.

\section{RESEARCH OBJECTIVE}

The objective of this study was to identify differences between blacks and whites who experienced kidney failure and received either standard or preemptive cadaver donor kidney transplants during the four year period between 2000 and 2004. There were three specific aims:

1. Specific aim 1 was to make a comparison by race of the demographic characteristic of PKT and conventional transplant recipients.

2. Specific aim $\mathbf{2}$ was to make a comparison by race of the health state, post transplant outcomes and time relative to transplantation of PKT and conventional transplant recipients. 
3. Specific aim $\mathbf{3}$ was to determine if a racial disparity exists in the receipt of PKT versus conventional cadaver kidney transplants.

\section{DEFINITIONS OF TERMS AND CONCEPTS}

The following were key terms and concepts used in this study:

1. chronic kidney disease (CKD): Term used to describe the whole continuum of progressive kidney disease, from chronic renal insufficiency (CRI) through and including end stage renal disease (ESRD).

2. chronic renal insufficiency (CRI): Condition in which the kidneys gradually lose their ability to perform their primary functions, the removal of wastes and extra fluid from the body.

3. dialysis: Artificial process of cleaning wastes from the blood when kidneys fail. The two major forms of dialysis are hemodialysis and peritoneal dialysis.

4. end stage renal disease (ESRD): Total kidney failure that requires dialysis to remove wastes and fluids from the bloodstream or kidney transplantation. For purposes of this investigation, ESRD occurs on the date of first service for dialysis.

5. hemodialysis: Use of a machine to clean wastes from the blood after the kidneys have failed. The blood travels through tubes to a dialyzer, which removes wastes and extra fluid. The cleaned blood then flows through another set of tubes back into the body. Hemodialysis is usually performed at a hospital, dialysis clinic, or doctor's office.

6. peritoneal dialysis: Process by which the blood is cleansed using the lining of the abdomen as a filter. A cleansing solution, called dialysate, is drained from a bag into 
the abdomen. Fluids and wastes flow through the lining of the abdomen and remain "trapped" in the dialysate. The dialysate is then drained from the abdomen, removing the extra fluids and wastes from the body. Typically, peritoneal dialysis can be performed by the patient at home.

7. pre-emptive kidney transplant (PKT): Process recognized as preemptive if it takes place before the initiation of chronic dialysis. For the purposes of this investigation any transplantation which occurred within six months of the date of first service for dialysis is preemptive.

\section{ASSUMPTIONS}

The following assumptions were made regarding this research:

1. The data in the ESRD Program Management and Medical Information System and the Renal Beneficiary and Utilization System (PMMIS/REBUS) database is reflective of the actual status of the population that these data represent.

2. The statistical analysis is reliable and valid.

3. Patients were placed on dialysis because of signs, symptoms, and laboratory indicators of ESRD, and not for other, non-medical reasons.

\section{LIMITATIONS OF THE STUDY}

The limitations of this research included the following:

1. The PMMIS/REBUS database is dynamic, and the results reported in the investigation therefore represent only a cross section of time. 
2. There is limited information on what is occurring in the individual market where patients receive care.

\section{ORGANIZATION OF THE STUDY}

This dissertation is organized into five chapters. In Chapter 1 the background of disparities in kidney transplantation and issues related to PKT are discussed. The purpose of the study is to explore the inequities of standard and PKT. Chapter 2 provides a review of the literature, which includes an analysis of research specifically focused on the differences between blacks' and whites' access to kidney transplantation. The literature review also includes a review of factors that affect the selection process for PKT. Chapter 3 describes the methods used in conducting the analysis, and Chapter 4 presents the results of these analyses. Chapter 5 concludes with a discussion of the findings and possible next steps advanced by this work. 


\section{CHAPTER 2. REVIEW OF THE LITERATURE}

\section{RACIAL DIFFERENCES IN ACCESS TO KIDNEY TRANSPLANTATION}

Racial differences in access to conventional or PKT involve several elements. Included among the most influential of these are when blacks are diagnosed with chronic kidney disease, when they are referred to a specialist, and when they are placed on the transplant waiting list. Each of these junctures in the transplant process reflects racial differences in access to transplantation, which will be reviewed.

Eggers (1995) went beyond previous works that had examined differences between black and white transplant populations. Instead of merely examining overall kidney transplant rates and waiting times to measure access to transplantation, he used three measures: time from renal failure to transplant, time from renal failure to waiting listing, and time from waiting list to transplantation.

Three data sets were matched for Eggers' analysis: (1) The Organ Procurement Transplant Network (OPTN) wait list and Health Care Financing Administration (HCFA) data sets and (2) the ESRD Program Management and Medical Information System (PMMIS). The OPTN wait list data consists of two files, the current active wait list file and the removals file that contains information on persons no longer on the active list. The wait list file used in this study contained 26,025 active records and the removals file 76,417 records. The HCFA ESRD PMMIS is a longitudinal file of ESRD patients entitled to Medicare benefits that is maintained by HCFA's Bureau of Data Management and Strategy. The ESRD PMMIS file used in this study was updated through April 1994. This updated file 
contained 582,330 people, the complete count of Medicare ESRD patients ever entitled since 1978.

Three measures of access to transplantation were derived for this analysis by Eggers (1995). In all three cases, a time-to-event model was used with measure specific censoring. There were a total of 79,527 persons under 55 years of age who initiated renal replacement therapy during the years covered by the study. Blacks were most likely to have their renal failure attributed to hypertension (34.1\%), and males comprised the majority of persons in all racial groups, ranging from $52.8 \%$ for Asians to $59.8 \%$ for blacks. There was little difference in the age distribution. Incidence overall was 81 per million population. Incidence was comparable between Asians and whites; however, compared with whites, blacks were almost four times as likely to suffer renal failure. Access to transplantation was inversely related to age, decreasing from $45.7 \%$ for persons less than 15 years of age to $8.1 \%$ for persons 45-54 years of age. At one year following renal failure, whites were almost four times more likely to have received a transplant than blacks. At five years post renal failure, fewer than one-third of blacks (30.3\%) had received a transplant, while well over one-half $(56.7 \%)$ of whites had received a transplant.

Black ESRD patients were least likely to get wait listed of all racial groups, with only $17.8 \%$ wait listed in the first year of renal failure. Transplantation rates after wait listing were highest for whites; over one-half were transplanted within one year of wait listing. However, the ethnic differences narrowed in subsequent years. For example, the black rate was only $68 \%$ as great as the white rate in the first year of wait listing. For those persons still not transplanted by the end of the second year, the transplantation rate for black patients was $90 \%$ as great as that for white patients. 
Race had a significant impact on all three measures of transplant access. Blacks were only $37 \%$ as likely as whites to get a transplant (including living donor). They were only $64 \%$ as likely as whites to get on the wait list and only $66 \%$ as likely to get a cadaver transplant after being wait listed. The author concluded that black ESRD patients lagged behind white patients in transplantation after wait list enrollment. A similar disparity existed in the primary step of getting on the wait list in the first place. The investigator concluded that no matter what measure of transplant access was used; blacks with ESRD fare worse than whites (Eggers, 1995). In addition, wait times following OPTN enrollment increased more for black patients than for any other racial group between 1988 and 1991.

Young and Gaston (2000) examined the influence of race on renal transplantation and summarized the effect of multiple interrelated scientific and political factors on the care of blacks with kidney failure. The major significance of this work was the authors' descriptive examination of the current United Network for Organ Sharing (UNOS) algorithm for organ allocation, which they proposed perpetuates racial disparity (Young \& Gaston, 2000). Specifically, the authors cited the allocation policy that requires ABO blood type as disadvantaging black candidates. This conclusion was attributed to the longer wait times for transplantation that were associated with $\mathrm{ABO}$ types that occurred more frequently in the black population (UNOS 1998 Annual Report). The longer wait time is a product of the relative weight of HLA antigen matching allocated by the UNOS allocation algorithms (Young \& Gaston, 2000). This algorithm awards points to wait listed transplant candidates based on several factors, including HLA match. When a kidney becomes available, the candidate with the most points is designated to receive that organ. Because an underlying assumption is that similarity in HLA antigen matching between donor and recipient 
optimizes outcomes, matching is the predominant variable determining the allocation of cadaver kidneys (Norman et al., 1995). Therefore the degree of donor recipient match is heavily weighted in the algorithm. Thus several immunologic factors combined to place blacks at a disadvantage in regard to the HLA match — with the net result being a preference for white candidates for transplantation (Young \& Gaston, 2000). Beatty, Mori, and Milford (1995) supported this observation, noting that blacks were only $28 \%$ as likely as whites to find a completely HLA matched donor among 500,000 potential donors. Young and Gaston (2000) pointed out that on the wait list containing more than $60 \%$ blacks, only 1 of 33 fully matched cadaver kidneys went to a black recipient. They went on to note that, nationally, $14 \%$ of all cadaver kidneys were transplanted into fully matched recipients, of whom $90 \%$ were white and only 9\% were black. Young and Gaston (2000) concluded that the primary benefit of the current allocation system is directed toward the predominantly white recipients with completely matched grafts.

In another examination of racial disparities in access to renal transplantation, Epstein et al. (2000) focused on whether the declining rate of transplantation in blacks was clinically appropriate or due to care underuse by blacks or overuse by whites. Specifically, the critical questions asked were whether blacks were less likely than whites to undergo necessary surgical procedures, and whether whites were more likely than blacks to undergo surgical procedures when non-surgical management was indicated.

This unique analysis was conducted by using a literature review and an expert panel to develop criteria for determining the appropriateness of renal transplantation for patients with ESRD. The criteria were based on the appropriateness of the presence or absence of factors constituting absolute or relative contraindications to transplantation. To develop the 
criteria, they used the study conducted by RAND (Park et al., 1986) and described by the Institute of Medicine (IOM Committee on Clinical Practice Guidelines, 1992).

Data on patients with ESRD were obtained from four regional ESRD networks that serve geographically diverse areas of Alabama; southern California; Michigan; and the District of Columbia, Maryland, and Virginia. To obtain a sample of 1,500 patients, the researchers selected a stratified random sample of blacks and whites from each region. They compared the demographic and clinical characteristics of patients in an analysis stratified according to sex as well as race. The t-test was used for continuous variables and the chisquare test for categorical variables. They used two logistic-regression models and a multivariate logistic-regression model to examine the effect of covariates on appropriateness ratings.

The results indicated that blacks were less likely than whites to be rated as appropriate candidates for transplantation according to appropriateness criteria (71 blacks [9.0\%] vs. 152 whites $[20.9 \%])$. Additionally, blacks were found to be more likely to have had incomplete evaluations (368 [46.5\%] vs. 282 [38.8\%], p < 0.001 for the overall chi-square). Among patients considered to be appropriate candidates for transplantation, blacks were less likely than whites to be referred for evaluation, $(90.1 \%$ vs. $98.0 \%, p=0.008)$, to be placed on a waiting list $(71.0 \%$ vs. $86.7 \%, \mathrm{p}=0.007)$, or to undergo transplantation $(16.9 \% \mathrm{vs} .52 .0 \%$, $\mathrm{p}<0.001)$. Among patients classified as inappropriate candidates, whites were more likely than blacks to be referred for evaluation $(57.8 \%$ vs. $38.4 \%)$, to be placed on a waiting list (30.9\% vs. $17.4 \%)$, and to undergo transplantation $(10.3 \%$ vs. $2.2 \%, p<0.001$ for all three comparisons). 
Epstein et al. (2000) concluded that racial disparities in rates of renal transplantation stemmed from differences in clinical characteristics that affected appropriateness as well as from underuse of transplantation among blacks and overuse among whites. In the opinion of the authors, reducing racial disparities would require efforts to distinguish their specific causes and the development of interventions tailored to address them.

The conclusions reached by Epstein et al. (2000) support the earlier conclusions reached by Alexander and Sehgal (1998), who documented a sequence of potential barriers along the clinical pathway to renal transplantation. It was the position of the researchers that intervention at any single point is unlikely to eliminate racial disparities. Their findings that blacks were less likely to be appropriate candidates for transplantation than were whites suggest that even if blacks and whites had equal access to renal transplantation, their rates of referral, placement on a waiting list, rate of transplantation or their cost break-even point might not be the same.

Epstein et al. (2000) readily acknowledged several limitations of their study. First, the number of patients in the underuse group considered to be appropriate candidates for transplantation was small, possibly allowing unstudied factors to bias the results. Second, appropriateness ratings varied among expert panels, and the number of persons in overuse and underuse categories would, therefore, likely vary according to the particular panel used. However, the researchers propose that this variation would not affect racial differences in ratings. Third, the study sample was restricted to persons between the ages of 18 and 54 years. Whereas a substantial proportion of patients receiving dialysis for the first time were 55 or older, there was also a substantial decline in rates of transplantation among older patients. Finally, the study examined a condition for which almost all patients in the United 
States have insurance coverage through Medicare and are in close contact with the medical care system through dialysis and transplantation two factors that would be expected to reduce racial disparities in care.

Foster et al. (2002) reviewed renal transplantation in blacks over a ten year period. Their objective was to evaluate the strategies instituted by a transplant center to decrease time on the waiting list and increase the rate of transplantation for blacks. The intervention consisted of a formal education program oriented toward blacks concerning benefits of living organ donation.

During the study period, from March 1990 to November 2001, data were obtained from 2,167 renal transplants; 944 were blacks (663 primary cadaver renal transplants and 253 primary living donor renal transplants). Outcome measures of this historical cohort study found median waiting time for cadaver renal transplant for whites was 391 days compared with 647 days for blacks. Foster et al. (2002) concluded that programs specifically oriented to improving volunteerism in blacks lead to a marked improvement in overall waiting time and in rates of living donation in the patient group. The median waiting times for cadaver renal transplantation were also significantly shorter. These programs markedly improved ESRD care for blacks by cutting in half the overall waiting time while still achieving comparable graft and patient survival rates. It should be noted that the results of this study were only qualitative, non-statistical comparisons that used a methodology for calculating waiting time that was different than that used by UNOS, which takes into account death on the waiting list. Additionally, some transplant programs do not register living donors with UNOS, possibly inflating overall waiting time. 
A racial difference in access to the kidney transplant waiting list has also been found in pediatric patients. Furth et al. (2000) sought to determine whether the increased time to transplantation for black pediatric patients was attributable not only to a shortage of suitable pediatric donor organs but also to racial differences. They conducted a national longitudinal cohort study of U.S.-Medicare-eligible pediatric ESRD patients. Study subjects included children and adolescents $<19$ years old at the time of their first dialysis between 1988 and 1993, who were followed though 1996. Patients who received living donor renal transplants were excluded from the study. The primary outcome measures were the time from first dialysis until activation on the kidney transplant waiting list and the likelihood of activation on the waiting list for black compared with white pediatric patients.

Furth et al. (2000) found that for the 2,162 white (60.7\%) and 1,122 black (31.5\%) patients studied using survival analysis, blacks were less likely to be wait listed at any given time in follow up. In multivariable analysis even after controlling for patient age, gender, socioeconomic status, geographic region, incident year of renal failure, and cause of ESRD blacks were $12 \%$ less likely to be wait listed than whites at any point in time (relative hazard: $0.88 ; 95 \%$ confidence interval; 0.79-0.97).

Among black patients, 28.6 patients were wait listed per 100 person-years of follow up, compared with 33.9 for whites. Two hundred fifty-two patients (7.7\%) were activated on the waiting list before their first dialysis; $76 \%$ of these patients were white. The cumulative incidence of patient wait listing according to race is shown in Fig. 2-1. Kaplan-Meier analyses demonstrated that at any point in time black patients were less likely than were white patients to be activated on the kidney transplant waiting list $(\mathrm{P}=.007$, log-rank test). The disparity was present early on and remained relatively constant over time. 


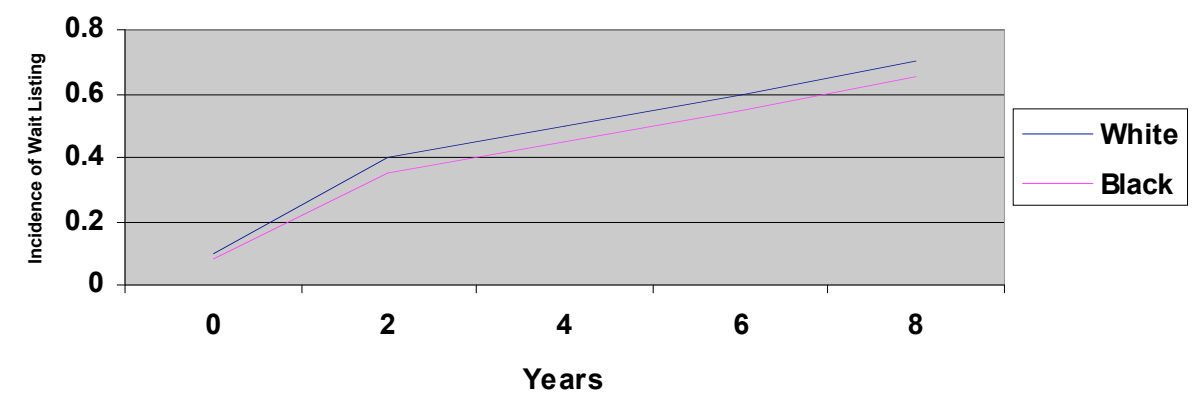

Figure 2-1. Cumulative incidence of wait listing for black and white pediatric patients after first dialysis for ESRD.

Source: Furth S.L., et al. Racial differences in access to the Kidney Transplant Waiting List for Children and Adolescents with ESRD. Transplantation, 2000; S237. Reprinted with permission.

To assess the independent effect of race on time from first dialysis until activation on the kidney transplant waiting list, Fruth et al. (2000) performed a Cox proportional hazards analysis and found that even after controlling for important confounders identified in the Kaplan-Meier analyses (including patient age, gender, socioeconomic status, assigned cause of ESRD, geographic region, and incident year of dialysis), blacks were still $12 \%$ less likely than whites to be activated on the kidney transplant waiting list (relative hazard: $0.88 ; 95 \%$ confidence interval [CI]: 0.79, 0.97).

Several limitations of the Fruth et al. (2000) study deserve mention. Any errors in the recorded dates of first dialysis and first wait listing would be expected to be random and not associated with patient race. This random misclassification would tend to minimize rather than exaggerate the racial differences in time from first dialysis for ESRD to activation on the wait list that the researchers saw. 
Fruth et al. (2002) concluded that racial disparities in access to the renal transplant waiting list existed when black children experienced delayed access to this therapy. Whether these disparities were attributable to differences in time of presentation to nephrologists, physician bias in identification of transplant candidates, or patient preferences warrant further study. This is the first known report that documents the racial differences in access to renal transplantation extended beyond the adult population to include children.

Young and Gaston (2002) reviewed published reports that examined the connection between race and the incidence of chronic renal failure, access to optimal therapy, and outcomes of renal transplantation. This research underscored the point that blacks with ESRD are at the epicenter of continued debate about access to transplantation of renal allograft. The literature reviewed in this area pointed out that the impact of race on delivery of care in ESRD remains controversial. According to the authors, it was the exaggerated incidence of kidney failure among blacks, along with the under-representation of those patients receiving cadaver renal allograft that continues to fuel the controversy. Young and Gaston's brief review was intended to summarize the impact of multiple interrelated scientific and political variables on blacks with kidney failure. Summarizing Young and Gaston's 2002 review, the incidence of ESRD in blacks was four times greater than that in whites, but blacks remained less likely than whites to be referred for or to undergo renal transplantation. Blacks remained disadvantaged in both access and outcomes. The authors concluded that further evaluation of underlying causes and development of specific remedies are warranted.

Ayanian et al. (2004) conducted research on physicians' beliefs about racial differences in referral for renal transplantation. According to Ayanian et al. (2004) a better 
understanding of physicians' views about racial differences in access to transplantation might help reduce disparities in care. Their study surveyed 278 nephrologists in four U.S. regions regarding quality of life and survival for blacks and whites undergoing renal transplantation and also the reasons for racial differences in access to transplantation. They also surveyed 606 of their own patients about their care. The physicians were less likely to believe that transplantation improved survival for blacks than whites $(69 \%$ versus $81 \% ; \mathrm{P}=0.001)$, but were likely to believe it improved quality of life ( $84 \%$ versus $86 \%$ ). Factors commonly cited by physicians as important reasons why blacks are less likely than whites to be evaluated for transplantation included patients' preferences (66\%), availability of living donors $(66 \%)$, failure to complete evaluations (53\%), and comorbid illnesses (52\%). Fewer physicians perceived patient-physician communication and trust $(38 \%)$ or physician bias $(12 \%)$ as important reasons. Black patients were less likely than white patients to report receiving some or a lot of information about transplantation $(55 \%$ versus $74 \% ; \mathrm{P}=0.006)$ when their physicians did not view patient-physician communication and trust as an important reason for racial differences in care. Aryanian et al. (2004) concluded that nephrologist' views about the benefits of renal transplantation and reasons for racial differences in access might have affected how they present this treatment option to black and white patients.

\section{PREEMPTIVE KIDNEY TRANSPLANTATION}

Until the mid-1980s, the general feeling was that PKT was associated with inferior results compared with post dialysis transplantation (Jacobs et al., 1977) but the literature remained sparse. However, the later published clinical experiences of PKT in adults (Migliori et al., 1987; Tegzess et al. 1987; Katz et al., 1991) suggested that the outcome 
might not be different from that following conventional cadaver transplantation. Migliori et al. (1987) reported a case control study of 132 preemptive transplants performed between 1968 and 1984. Those from cadaver donors (36 transplants) had relatively poor outcomes, a finding which was attributed to the high number of diabetics in this group. Katz et al. (1991) reported 85 consecutive preemptive transplants ( 47 and 38 from living and cadaver donors, respectively) between 1981 and 1988. Patient and graft survival rates were not different from those of the controls for the group as a whole or for living and cadaver donors analyzed separately. However, according to this investigation the preemptively transplanted group experienced significantly more rejection episodes attributed to noncompliance.

With the work of Tegzess (1987), Migliori (1987), and Katz (1991) leaving questions about PKT unanswered, Roake et al. (1996) conducted an analysis to compare the results of conventional cadaver renal transplantation with PKT at the Oxford Transplant Center. They sought to establish whether or not PKT could be justified on the basis of clinical outcome. For the purposes of their analysis Roake et al. (1996) defined PKT as the first transplantation before the need for chronic dialysis, including patients in whom the first dialysis was no more than 48 hours before transplantation. The analysis was a retrospective case-control study, subject to the risk of bias inherent in this type of analysis. The controls were selected, as far as possible, to be well matched to the PKT group, but some significant differences were present with respect to several variables that could have potential impact on graft survival. Furthermore, as a direct result of the study design, the controls developed ESRD failure at an earlier age than the PKT group, possibly as a consequence of more aggressive primary disease and this difference may have influenced patient survival. 
Patients who underwent PKT between June 1976 and December 1994 at the Oxford Transplant Center were compared with matched controls of first cadaver transplant recipients who were dialysis dependent when transplanted. The 116 patients in the PKT cohort were well matched to the control group with respect to sex, and blood group, and HLA match, degree of sensitization, donor age, immunosuppression, and year of transplantation. Both patient and graft survival were significantly better in the PKT group Differences in graft survival did not appear to be explained completely by better patient survival. Among surviving grafts there were no significant differences in graft function, as assessed by 1,2 , and 3 year plasma creatinine levels. Roake et al. (1996) concluded that PKT appeared to be safe and might even be associated with superior graft survival when compared with conventional transplantation. In a cautionary admonishment, they stated that early inclusion on a transplant waiting list with a view to PKT could be justified with respect to the clinical outcomes, but the financial costs and implications for the utilization of cadaver donor kidneys must also be considered.

By 2000, the research on PKT had shifted to an argument against waiting until dialysis. Papalois et al. (2000) acknowledged that PKT had not been favored in some centers because of concern about possible increased noncompliance and allegedly inferior long term results and analyzed their experiences to determine whether such concerns were justified. This research was an extension of previously reported research (Migliori et al., 1987) that found no significant disadvantages with PKT. In the follow up study the purpose of the analysis was to assess the potential benefits of PKT for long term patient and graft survival rates as well as for post transplantation quality of life. Papalois et al. (2000) reviewed their centers' experience with 1,849 primary adult kidney transplants from January 1, 1984 to June 
30, 1998. The analysis included 385 PKT and 1,464 non- PKT. The results were subdivided by donor source: cadaver and living donor. The PKT patients tended to be younger, but otherwise the two groups were similar.

The 5-year actuarial patient survival rate was superior for PKT patients regardless of donor source $(96.6 \%$ vs. $76.6 \%, p=0.001$ for cadaver transplants and $93.3 \%$ vs. $89.5 \%, p=$ 0.02 for living donor transplants). The results were significantly higher for PKT recipients compared with recipients undergoing dialysis for $<1,1-2$, and $>2$ years pre-transplant for both cadaver and living donor transplants. The conclusions reached were that PKT patients did not seem to have higher rates of noncompliance than those receiving dialysis. The results also seemed to indicate superior outcomes for PKT patients than for those who underwent some period of dialysis, supporting the contention that renal failure patients should, if possible, undergo transplantation before chronic dialysis. The quality of life for the PKT patients and those who received dialysis did not differ, nor did the post transplantation employment status. The results clearly refuted the argument that PKT decreased the quality of life or disabled PKT recipients. The superior outcome associated with PKT raised the issue of optimal timing for transplantation.

Beginning where Papalois et al. (2000) left off, Kasiske et al. (2002) further examined whether PKT actually was beneficial and, if so, who benefited. Using UNOS and USRDS data, they examined the characteristics of patients who received PKT. They also examined whether the effects on outcomes were similar in both cadaver and living donor transplant recipients, and whether these effects were independent of recipient age, year of transplantation, and other factors. The analysis retrospectively examined 38,836 first kidneyonly transplants between 1995 and 1998. Surprisingly, 39\% of the PKT were from cadaver 
donors; however, it should be noted that the proportions of cadaver donor transplants that were PKT changed very little-from $7.3 \%$ in 1995 to $7.7 \%$ in 1998 .

In the study of Kasiske et al. (2002), the researchers found that there was a greater likelihood of PKT among patients who (1) had a living donor; (2) were younger than 18 years old; (3) were white; (4) were not Hispanic; (5) were better educated; (6) were working full time; (7) had a primary payer other than Medicare; and (8) had 0 to 1 HLA-antigen mismatches. PKT was relatively more likely among children in this study, given that every effort is made to transplant children as soon as possible to improve their growth and development. Patients who received PKT were more likely to be employed both before and after transplantation than patients who did not receive PKT. Race and education were each independently associated with preemptive transplantation. One of the strongest correlates to preemptive transplantation was the primary source of payment. Patients who had Medicare as the primary payer were much less likely to receive preemptive transplantation. As the researchers pointed out, having Medicare as the primary payer could have been a surrogate for other factors, such as ethnicity. They concluded that the need to rely on Medicare itself may have discouraged PKT.

In conclusion, the results of this study (Kasiske et al. 2002) strongly suggested that PKT is beneficial. The reason for this additional, long term benefit associated with PKT remained unclear, but the researchers hypotheses that it could be related to the avoidance of one or more comorbidities, e.g., cardiovascular disease, that may have otherwise developed during treatment with maintenance dialysis.

PKT is associated with allograft survival advantage and is promoted in part because of this association. Because the basis for the allograft survival advantage in preemptive 
recipients remains unclear, Gill et al. (2004) further explored this relationship by focusing on the possibility that the advantages seen in PKT patients were due to a lead time bias derived from the earlier transplantation of patients with preserved native kidney function. Other possibilities included less rapid loss of kidney function after transplantation, or the possibility that the advantage could be explained simply by longer patient survival of PKT patients.

In attempting to determine why PKT recipients had an allograft survival advantage, Gill et al.(2004) research focused their research on a comparison of the glomerular filtration rate (GFR) six months after transplantation and the subsequent rate of loss of kidney function as defined by the annualized change in GFR $\left(\mathrm{mL} / \mathrm{min} / 1.73^{2} /\right.$ year $)$ in 5,966 preemptive and 34,997 non-preemptive recipients. Linear regression methods were applied to serial GFR estimates after transplantation to determine the annualized change in GFR. Multiple regression was used to determine the independent effect of preemptive transplantation upon the annualized change in GFR. The results showed that the mean GFR 6 months after transplantation was similar among PKT $\left(49.5 \pm 15.7 \mathrm{~mL} / \mathrm{min} / 1.73 \mathrm{~m}^{2}\right)$ and non-preemptive $\left(49.2 \pm 14.7 \mathrm{~mL} / \mathrm{min} / 1.73 \mathrm{~m}^{2}\right)$ recipients $(\mathrm{P}=0.37)$. In multivariate analysis, preemptive recipients had a slower decline in GFR $\left(0.28 \mathrm{~mL} / \mathrm{min} /\right.$ year $/ 1.73 \mathrm{~m}^{2} ; 95 \%$ confidence interval $0.11,0.46 ; \mathrm{P}=0.002)$. However, this difference was of modest clinical significance and would not explain the allograft survival advantage of preemptive transplantation. Having found no meaningful significance, the researchers concluded that neither the preservation of native kidney function nor differences in the rate of loss of kidney function explained the superior allograft survival of preemptive recipients. They concluded with the hypothesis that the apparent allograft survival advantage of PKT is the result of improved patient survival 
resulting from patient selection or the reduced severity of comorbid disease associated with avoidance of dialysis.

The Gill et al. (2004) analysis found that PKT was more common among non-blacks. Other reports in the literature also indicate that whites are more likely than blacks to have a living donor. In addition, PKT recipients were found to be younger, female, and non-HLA mismatched patients, and patients with polycystic disease.

Kasiske et al. (1998) conducted an analysis specifically focused on race and socioeconomic factors influencing early placement on the kidney transplant waiting list. This cohort study investigated whether there were inequities in the current system for listing patients for cadaver renal transplantation, using bivariate and multivariable analyses to identify factors associated with early registration before initiation of dialysis. While this analysis did not focus on PKT specifically, the examination of waiting times is relevant in creating a perspective for other literature to be reviewed and the analysis conducted in the current research that looked at the differences in PKT rates between blacks and whites.

Kasiske et al. (1998) noted that UNOS has established a system for allocating kidneys for cadaver transplantation that is designed to be both equitable and efficient. The UNOS point system for allocating kidneys awards points for waiting time, so that individuals who have waited longer are more likely to receive a kidney, all other factors being equal (UNOS Policy 3.5: Allocation of Cadaver Kidneys, 1997). Based on this policy, it is clear that physicians and patients want registration to take place as soon as possible, to begin accruing waiting time. It is certainly an advantage to register for transplantation before initiating maintenance dialysis. According to the authors, registering before dialysis theoretically may allow patients to receive a transplant before initiating dialysis, and thereby obviating the need 
for permanent dialysis access. However, given the long waiting time, PKT is usually not possible with a cadaver kidney. Although the research perspective articulated by Kasiske et al. (1998) was that registering before transplantation usually offers no practical advantage other than waiting time accrual, Kasiske et al. (1998) used registration before maintenance dialysis initiation as an indicator of early listing for cadaver renal transplantation. Because listing before dialysis may be advantageous with regard to waiting time accrual, the investigators sought to determine whether there were differences in patients who did or did not register before dialysis. Major differences in patients who registered before versus those who registered after initiating dialysis could indicate potential inequities in the allocation system, and/or in access to health care in general.

The analysis of Kasiske et al. (1998) included all patients who registered with UNOS on the OPTN kidney and kidney pancreas waiting list between April 1, 1994, and June 30, $1996(n=41,596)$ from all 238 UNOS renal transplant centers. The information in the database was collected using the UNOS Transplant Candidate Registration Form. The research included the following variables: gender, age, history of previous kidney transplant, highest education level achieved, ethnicity, employment status, projected payment source, registration at a high volume center, diabetes/insulin dependent, kidney versus kidney pancreas registration, functional status at registration, and the year of listing $(1994,1995$, 1996). The statistical analysis included both bivariate and multivariable analyses (Kasiske et al., 1998).

In the univariate analysis, of all the registrations - 41,596 (18.4\%)—were not yet on dialysis. A number of characteristics were different between those not yet on dialysis and those on dialysis at the time of listing. Although $59.3 \%$ of all registrations were male, of 
those not yet on dialysis, only $57.7 \%$ were male. Those not yet on dialysis were younger and more likely to have had a prior transplant. They were better educated and were more often white. They were more likely to have private insurance, listed at a high volume center, to be diabetic. The multivariable analysis revealed that for all registrations, the odds of being listed before undergoing maintenance dialysis were $15 \%$ greater for females compared with males. Individuals with a prior transplant were $80 \%$ more likely to be listed before dialysis. The more years of schooling a patient had, the more likely the patient was to have been listed before dialysis. Blacks were $47 \%$ as likely as whites to be listed before dialysis. Individuals employed full time were more likely to be listed before dialysis compared with those who were working less than full time. Compared with patients with other payment sources, those whose primary source of payment was Medicare were only $34 \%$ as likely, whereas those with private insurance were $21 \%$ more likely to be listed before dialysis. Of special note was that 0 to 8 years of education correlated with a greater likelihood of being listed before dialysis, compared with a reduced likelihood when the larger population of patients was analyzed.

Kasiske et al. (1998) assumed that pre-dialysis at the time of listing could be used as an indicator of placement on the waiting list earlier in the course of renal disease than registration of patients who were already on dialysis. They also assumed that patients were placed on dialysis because of signs, symptoms, and laboratory indicators of ESRD, and not for other, non-medical reasons. They concluded that it is advantageous for patients to be placed on the waiting list as soon as possible, because waiting time adds points to the total UNOS point score and thereby helps determine how long a patient may wait for a kidney. The greater the number of points the more likely the patient will be transplanted soon. 
Listing patients as soon as possible is also advantageous to centers that may wish to transplant as may patients as soon as possible. As a matter of fact in the Kasiske et al. (1998) study, a logistic regression model testing for center effect did indeed find that some centers listed patients sooner (before dialysis) more often than other centers.

Kasiske et al. (1998) found that race and socioeconomic factors influenced early listing. Patients who were younger, better educated, white, and working full time, and who had better insurance coverage were more often listed before dialysis (compared with patients who were older, less well educated, or a racial or ethnic minority working less than full time, and who had less insurance coverage). Kasiske et al. (1998) concluded that early listing can now be added to a growing number of steps along the road to renal transplantation that seem to be influenced by ethnicity, gender, and socioeconomic factors. Identification of potential candidates for renal transplantation is influenced by ethnicity, gender, employment status, and education level (Soucie et al., 1992). Furthermore research of Soucie et al. (1992) supports the proposition that even after having been placed on the cadaver transplant wait list the, ethnicity, age, and gender of transplant candidates have been shown to affect the waiting time.

Several recent studies reflected in this literature review have confirmed the survival advantage for renal transplant patients over those waiting on a transplant receiving maintenance dialysis. Meier-Kriesche et al. (2000) furthered this work by investigating the hypothesis that longer waiting times are more deleterious than shorter waiting times, that is, their objective was to detect a "dose effect" for waiting time. The issue of waiting times is addressed herein due to the direct impact this factor has on the decision for PKT. 
Meier-Kriesche et al. (2000) included 73,103 primary adult renal transplants registered at the USRDS registry from 1988 to 1997 with the primary end points of death with functioning graft and death censored graft failure. All Cox proportional hazard models were corrected for donor and recipient demographics and other factors known to affect outcome after kidney transplantation. The study sample consisted of patients who underwent solitary primary (multiorgan and secondary transplants were excluded from the analysis) renal transplantation. Waiting time on dialysis was calculated from the start of maintenance dialysis treatment to transplant date. The impact of waiting time on dialysis prior to transplantation on the primary end points was analyzed both as a continuous variable and as a categorical variable. The results showed increasing waiting time on dialysis was a significant risk factor for death-censored graft loss after renal transplantation $(\mathrm{P}<0.001)$. Being on dialysis for up to 6 months prior to transplantation conferred a 17\% increased risk for deathcensored graft loss as compared with PKT when adjusted for all factors considered in this analysis. Dialysis treatment for 6 to 12,12 to 24 , and 24 to 36 months prior to renal transplantation conferred a $37 \%, 55 \%$, and $68 \%$ higher risk for death-censored graft loss, respectively. Beyond 36 months of dialysis, there remained a significantly increased risk of death censored graft loss as opposed to PKT $(\mathrm{P}<0.001)$; however the relative increase beyond 36 months from $68 \%$ to $70 \%$ to $74 \%$ was small and not statistically significant. Other significant risk factors for death-censored graft loss were black recipient $(\mathrm{P}<0.001)$, black donor $(\mathrm{P}<0.001)$, higher donor age $(\mathrm{P}<0.001)$, higher HLA mismatch $(\mathrm{P}<0.001)$ and diabetes as the cause of ESRD $(\mathrm{P}<0.001)$. When adjusting for all factors being considered in this analysis increasing waiting time on dialysis was also a significant risk factor for patient death with a functioning graft after renal transplantation $(\mathrm{P}<0.001)$. 
Meier-Kriesche et al. (2000) demonstrated that waiting time on dialysis is a strong, independent risk factor for decreased patient survival as well as decreased death-censored graft survival following renal transplantation. This effect was independent of all other factors in the model (including recipient age, ethnicity, original disease, and donor characteristics) and likely reflects a true negative effect of waiting time on dialysis. This effect appeared to be "dose dependent" the longer the waiting period the greater the risk for either of these negative outcomes. Meier-Kriesche et al.(2000) provided strong support for the hypothesis that patients who reach ESRD should receive a renal transplant as early as possible in order to enhance their chances of long term survival.

Failure to complete the medical evaluation for renal transplantation may impede access to transplantation and preclude the possibility of PKT. Research conducted by Weng et al. (2003) sought to (1) characterize completion rates of the transplantation medical evaluation and (2) determine factors associated with completion of the evaluation. The research was conducted based on the hypothesis that patients not yet on dialysis therapy complete the evaluation process more quickly than patients receiving dialysis. Between September 2002 and September 2003, patients evaluated for renal transplantation at the Hospital of the University of Pennsylvania (Philadelphia, PA) were enrolled in an observational, prospective, cohort study. Of 356 patients who presented for evaluation, 175 patients were included in this analysis. The electronic medical record (EMR) was examined after all patients had the opportunity to accrue a minimum of 6 months of follow-up since their initial evaluation. The transplantation evaluation was considered complete if the patient was placed on the UNOS waiting list for a deceased donor renal transplant or the patient received a renal transplant, whichever occurred first. As standard practice for this transplant 
center, all patients who successfully completed the medical evaluation were listed for a deceased donor renal transplant. Therefore, the transplant center staff considered the listing for deceased donor transplantation to signify successful completion of the pre-transplantation workup.

Weng et al. (2003) examined the association between dialysis status at the initial transplantation evaluation visit and time until completion of the medical evaluation. A Cox proportional hazard model was fit to examine the relationship between baseline covariates, particularly dialysis status, and time to completion of the transplantation evaluation. Of the 175 study participants, a slight majority (54.3\%) were receiving maintenance dialysis at the time of initial transplantation evaluation. Patients receiving dialysis were more likely to be black, lack a college education, report disability or unemployment, have a lower annual household income, and list Medicare as their medical insurance compared with patients not yet on dialysis therapy. In an unadjusted Cox analysis, dialysis status at the time of the initial transplantation was associated with a slower rate of completion of the evaluation. The association between dialysis status at the time of the initial transplantation evaluation and time to completion of the transplantation evaluation did not persist in the multivariable model (adjusted HR, 0.92; 95\% CI, 0.60 to $1.42 ; \mathrm{P}=0.72$ ). After adjusting for other factors, black ethnicity remained associated with decreased rates of completion of the transplantation evaluation (adjusted HR, $0.63 ; 95 \% \mathrm{CI}, 0.40$ to $1.00 ; \mathrm{P}=0.05$ ).

Weng et al. (2003) had a novel prospective recruitment of all patients who appeared for transplantation evaluation, regardless of patient dialysis status or availability of living donors. Previous investigations of the transplantation process were restricted to patients either receiving maintenance dialysis (Alexander et al., 1998; Ayanian et al., 1999) or 
seeking deceased donor transplants (Kasiske et al., 1998; Alexander et al., 2002). The broad, inclusive criteria of Weng et al. (2005) permitted examination of the impacts of dialysis status and type of transplant donor, two factors that influence patient and allograft survival on completion of the transplantation evaluation. These factors have not been previously studied extensively as determinants of access to transplantation. Another novel feature of the study by Weng and coworkers (2005) is its focus on the medical evaluation for renal transplantation process.

Weng et al. (2005) admitted that the study had important limitations including, but not limited to, it's possibly being underpowered to detect differences in the completion of the transplantation evaluation by dialysis and non-dialysis patients. Second, because the study reflected the referral population of a single transplant center and the practices of the center's transplant team, these results were not necessarily generalizable to other transplant centers. Third, although they collected information on many potential confounders, residual confounding remained a possibility. In particular, they had limited ability to adjust for comorbidity and case-mix severity. Specifically, greater comorbidity among blacks could have contributed to the slow rate at which blacks completed the transplantation evaluation. To minimize this confounding, they recorded the number and type of tests and evaluations requested by the transplant team. After adjustment for these requested tests and evaluation, blacks still remained associated with decreased rates of completion of the transplant evaluation.

In summary, Weng et al. (2005) concluded that the completion of the medical evaluation for transplantation was unrelated to dialysis status. The process was slower in blacks than whites and was associated with various socioeconomic factors. Rapid 
completion of the transplantation evaluation process would benefit all potential candidates for renal transplantation, irrespective of dialysis status or ethnicity. Additional studies are needed to help determine the root causes of variations in completion of the medical evaluation and devise appropriate interventions (Powe \& Boulware, 2002). Interventions that expedite the medical evaluation while retaining its thoroughness may improve patient access to renal transplantation, increase rates of PKT, and possibly lead to better outcomes. 


\section{CHAPTER 3. METHODOLOGY}

\section{DATA OVERVIEW}

The current research is a historical cohort study of all patients who experienced ESRD and/or received a cadaver kidney transplants between January 1, 2000 and December 31, 2003. The patients were identified using data acquired from the standard analytic files (SAF) of the USRDS. Patients from the dataset were included in the study if they (1) were designated by CMS as having ESRD, (2) had their first ESRD service and/or underwent a cadaver kidney transplant between January 1, 2000 and December 31, 2003, (2) were either black or white, and (3) were not $<19$ years old at the time of transplant. Patients were excluded if they had more than one kidney transplant, or multi-organ transplants were obtained or if their transplants were obtained from living donors.

The data sources for this study were obtained from the 2000-2004 United States Renal Data System Database (USRDS) System. The main objective of the USRDS database is to use all relevant ESRD data to create an integrated and consistent database system for outcomes research. The database includes ESRD patient demographic and diagnosis data, biochemical values, dialysis claims, and information on treatment history, hospitalization events, and physician/supplier services.

The data used by the USRDS originates from Center for Medicare Services (CMS), United Network for Organ Sharing (UNOS), the Centers for Disease Control (CDC), the End Stage Renal Disease (ESRD) Networks, and the USRDS special studies section. The major source of ESRD patient information for the USRDS is the CMS Renal Beneficiary and Utilization System (REBUS), which was adopted in 1995 as the On-Line Transaction 
Processing (OLTP) system from its predecessor, the Program Management and Medical Information System (PMMIS) database. The PMMIS/REBUS database contains demographic, diagnosis, and treatment history information for all Medicare beneficiaries with ESRD.

Data for input into the database that was utilized for this analysis was derived from the following sources that are summarized in the USRDS Researcher's Guide (2005). A quoted description of each from the Guide follows:

\section{- CMS Medical Evidence Form (CMS-2728)}

The CMS Medical Evidence Form is completed by the renal provider for each new ESRD patient, and is sent to CMS through the ESRD Networks. It serves to establish Medicare eligibility for individuals who previously were not Medicare beneficiaries, reclassify previously eligible Medicare beneficiaries as ESRD patients, and provide demographic and diagnostic information on all new ESRD patients regardless of Medicare entitlement. Before 1995, dialysis units and transplant centers were required to file the Medical Evidence Report only for Medicare eligible patients. With the adoption of the newly revised form in 1995 , however, providers are now required to complete the form for all new ESRD patients regardless of Medicare eligibility status. The revised form also contains new fields for comorbid conditions, employment status, race (the categories have been expanded), ethnicity, and biochemical data at the start of ESRD (USRDS Researcher's Guide, 2005; 21). 


\section{- CMS ESRD Death Notification Form (CMS-2746)}

Like the Medical Evidence Report, the Death Notification Form is data rich, and its completion by renal providers is enforced by CMS. Providers usually have 45 days to report ESRD death events to their respective ESRD Networks, providing information about the place, time, and cause of death. Data are thus available to the USRDS Coordinating Center to conduct research on cause-specific mortality outcomes (USRDS Researcher's Guide, $2005 ; 21)$.

\section{- CMS Medicare Enrollment Database (EDB)}

The CMS Enrollment Database is the designated repository of all Medicare beneficiary enrollment and entitlement data, including current and historical information on beneficiary residence, Medicare as Secondary Payer (MSP) status, and Health Insurance Claim/Beneficiary Identification Code (HIC/BIC) cross-referencing (USRDS Researcher's Guide, 2005; 21).

\section{- CMS Paid Claims Records}

Inpatient transplant and outpatient dialysis claims records are sometimes used to identify new ESRD patients for whom no Medical Evidence Report has been filed. These patients, who are most likely to be nonMedicare patients or beneficiaries who develop ESRD while already on Medicare because of old age or disability, will eventually be entered into the PMMIS/REBUS database-and hence the USRDS-database through the claims records. For patients without Medical Evidence records, these claims are the only reliable information from which to determine first service dates for 
ESRD. These paid claims records, however, are only a supplement to-not a replacement of-other sources of information on incidence and prevalence (USRDS Researcher's Guide, 2006; 21-22).

\section{- UNOS Transplant Database}

CMS began collecting data on all Medicare kidney transplants in the early 1980s. In 1988, UNOS was created to provide a national system for allocating donor organs and to maintain a centralized data depository on organ transplantation. UNOS also began collecting data on all transplants. Subsequently, these two collection efforts were consolidated in 1994, and UNOS became the sole source on transplant donors and recipients. The CMS and UNOS transplant data files overlap for 1988-1993, and some patients with Medical Evidence Reports indicating transplant as the initial modality are not included in either file. To resolve the conflicts among these three sources, the USRDS has adopted the following procedure: Prior to 1988 all transplant events found in CMS PMMIS/ REBUS Transplant files are used. After 1994, all transplant events found in the UNOS files are used. Between 1988 and 1993, all transplant events found in the UNOS files are used while additional transplant events are taken from the CMS PMMIS/REBUS Transplant file only if they occur at least 30 days (either side) of a previously accepted transplant event. Additionally, transplant events associated with the reported incident transplant patients from the Medical Evidence Report (CMS-2728) are taken if they also occur at least 30 days (either side) of a previously accepted transplant event. The transplant events found in the Transplant file 
of the USRDS SAF Core CD are thus all unique events derived from the UNOS, CMS PMMIS/REBUS Transplant, and Medical Evidence record files (USRDS Researcher's Guide, 2005; 21).

\section{- CMS ESRD Standard Analytical Files (SAFs)}

CMS SAFs contain data from final action claims, submitted by Medicare beneficiaries, in which all adjustments have been resolved. For Part A institutional claims, the USRDS uses the following 100\% SAF claims:

Inpatient

Outpatient

Skilled nursing facility (SNF)

Home health agency (HHA)

Hospice

For Part-B physician/supplier 100\% SAF claims:

Physician/supplier

Durable medical equipment (DME)

CMS SAFs are updated each quarter through June of the next year, when the annual files are finalized. Datasets for the current year are created six months into the year and updated quarterly until finalized at 18 months, after which files are frozen and will not include late arriving claims. Annual files are thus approximately $98 \%$ complete. The USRDS 2005 ADR includes all claims up to December 31, 2003. Patient-specific demographic and diagnosis information, however, includes data as recent as October 2004 (USRDS Researcher's Guide, 2005; 22).

The structure of the USRDS database is presented in Fig. 3-1. 


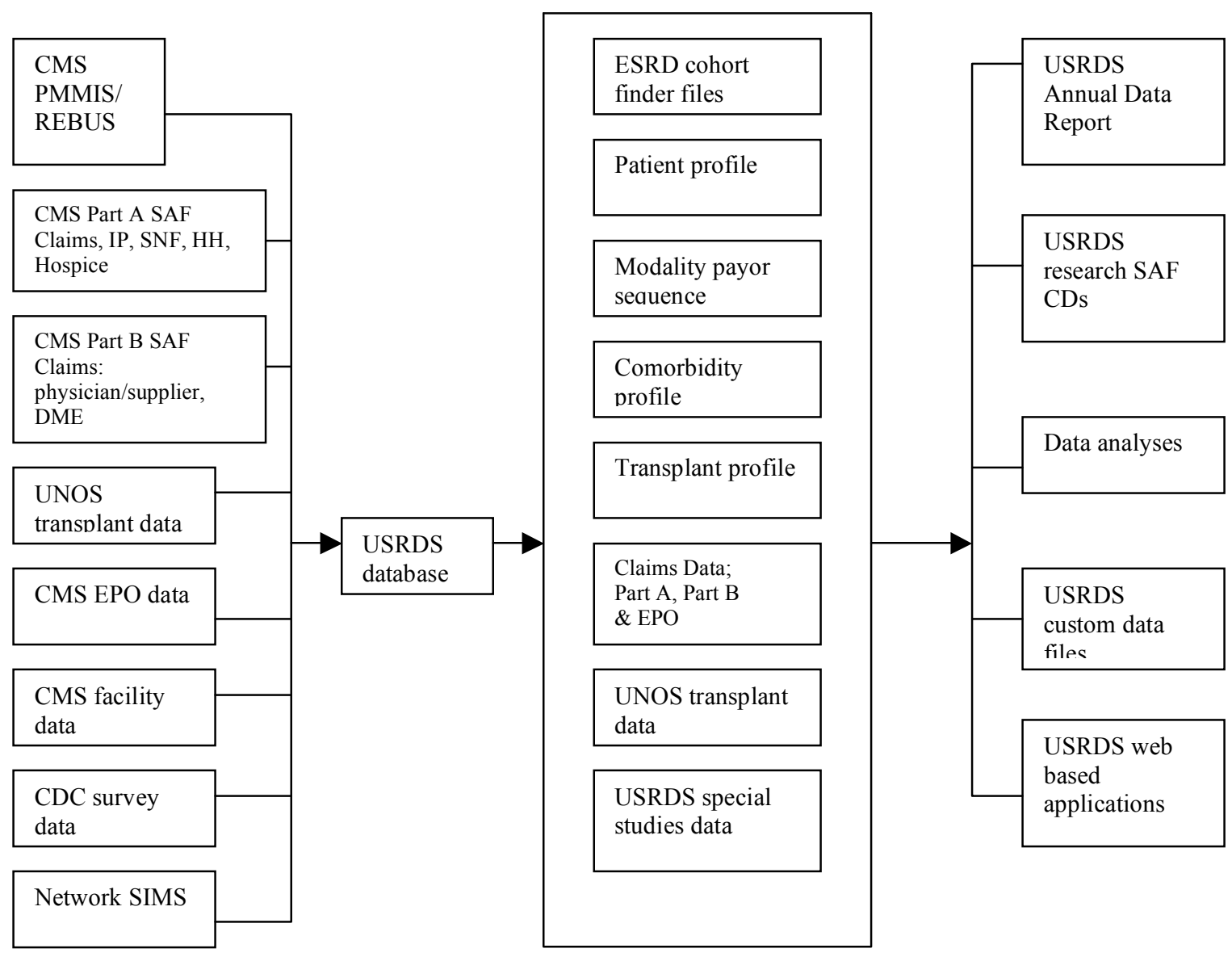

Figure 3-1. Structure of the USRDS database.

Source: United States Renal Data System Researcher's Guide to the USRDS Database. National Institutes of Health, National Institute of Diabetes and Digestive and Kidney Diseases, Bethesda, MD, 2005. Required notice: "The data reported here [i.e., in this dissertation] have been supplied by the United States Renal Data System (USRDS). The interpretation and reporting of these data are the responsibility of the author(s) and in no way should be seen as an official policy or interpretation of the U.S. government." 


\section{PROTECTION OF HUMAN SUBJECTS}

This study is a secondary data analysis of the USRDS database. Prior to obtaining any data from USRDS/CMS, approval from Thee University of Tennessee Health Science Center Institutional Review Board (IRB) was obtained (see Appendix A).

\section{STATISTICAL ANALYSIS}

The conceptual framework that guided the statistical analyses is depicted in Fig. 3-2. This framework begins with the race phenomenon being examined in the context of PKT. In outlining the knowledge state of ESRD the framework identifies the components, causes of ESRD and demographic characteristics that may play a part in the diagnosis of ESRD. The diagnosis of ESRD leads to a referral to a nephrologists, which is the empirical phase of this research under examination and the theoretical fork in the road that leads either to a PKT or dialysis and/or placement on the transplant waiting list. The framework identifies the pathway (depending on whether the patient receives a PKT or not) to whether the patient survives and or dies.

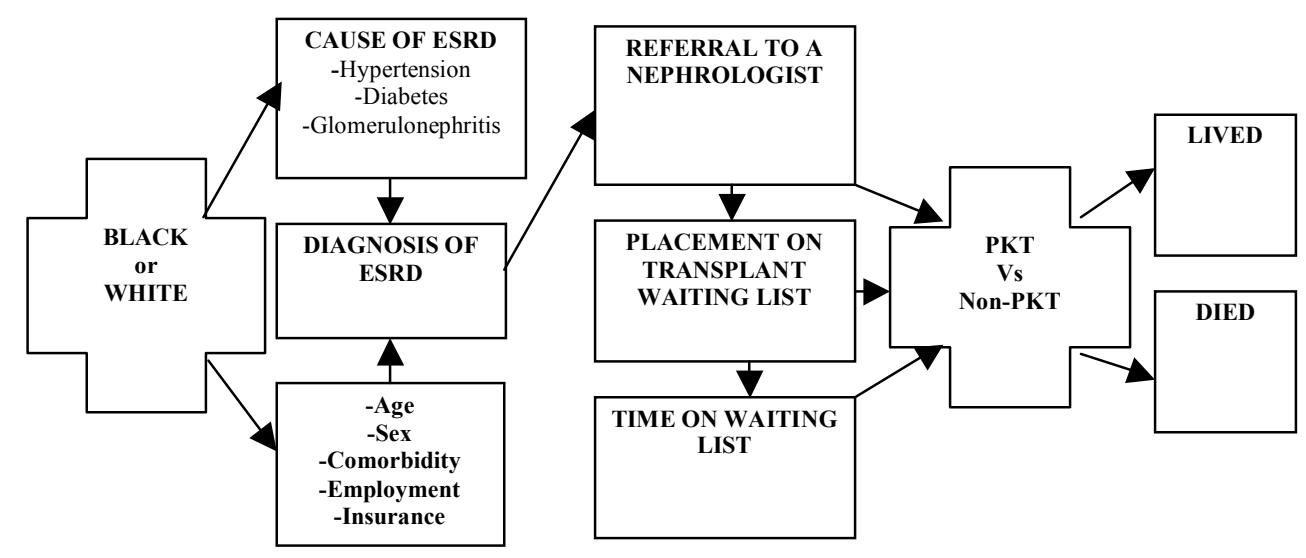

Figure 3-2. Conceptual framework. 
Separate analyses were carried out for recipients of cadaver PKT and cadaver conventional kidney transplants grouped by patient's race. I first examined associations between patient characteristics listed in Fig. 3-2 and PKT or conventional kidney transplant, one variable at a time, assessing statistical significance with a $X^{2}$ test (categorical data) or $\mathrm{t}$ test (continuous data). A multivariate, logistic regression analysis was used to examine the relative influence of the variables. This analysis was designed to assess which of the patient characteristics were independently associated with PKT and conventional kidney transplant.

The effect of race on PKT and conventional kidney transplant was also examined, for graft and patient survival using the Kaplan-Meier method with a log-rank test for statistical significance. All analysis was carried out using the statistical software package SAS version 9.1.4 (SAS Institute, Inc., Cary, NC). All results were considered statistically significant if $\mathrm{P}$ $<0.05$.

\section{KEY CONCEPTS IN ESRD}

\section{Who Is an ESRD Patient?}

An ESRD patient is one who has developed chronic renal failure and requires kidney replacement treatment, dialysis or transplant to sustain life. This is not to be confused with acute renal failure, in which the patient is expected to recover renal function after several weeks or months. Those patients who experience acute renal failure and are on dialysis for days or weeks, but who subsequently recover kidney function, are, as much as possible, excluded from the ESRD database. A person is identified as having ESRD when a physician certifies the disease on a medical evidence form (CMS 2728), or when there is other evidence 
that the person has received chronic dialysis or a kidney transplant. The medical evidence form is completed by renal a renal provider, not only to register the patients in the CMS ESRD database, but also to apply for their Medicare eligibility if they have not previously been eligible. Patients who die soon after kidney failure without receiving dialysis treatment are occasionally missed (USRDS Researcher's Guide, 2005).

\section{First ESRD Service Date}

The first ESRD service date (FSD) is the single most important data element in the USRDS database, and each patient must, at a minimum, have a valid FSD. This date is used to determine the incident year of each new patient and the first year in which the patient is counted as prevalent. The date 90 days after the FSD is used as the starting point for most patient survival outcomes analyses. This special rule is necessary for all ESRD patients, who are covered by Medicare as payer, to be given a fair chance of generating Medical services due to potential delay of the Medicare eligibility application process. Furthermore, it also provides an adequate time window for each patient to finally settle on a stable and suitable dialytic treatment modality. The FSD is derived by taking the earliest of the date of the start of dialysis for chronic renal failure, as reported on the Medical Evidence form, the date of a kidney transplant, as reported on a CMS or UNOS transplant form, a Medical Evidence form, or a hospital inpatient claim, or the date of the first Medicare dialysis claim. Most FSDs are derived from the Medical Evidence form. In the absence of this form, the date of the first Medicare dialysis claim or transplantation usually supplies the FSD. 
In the few cases in which the date of the earliest dialysis claim is earlier than the first dialysis date reported on the Medical Evidence form, the earliest claim date is used as the FSD. To establish the date of first ESRD service information in several data sources must be evaluated. REBUS contains the first ESRD service date in its identification record in the Medical Evidence record. The REBUS Quarterly Dialysis record is a summary of dialysis billing information, and can also be used to establish first ESRD service date in the event of missing data in other files. Finally, information on the first service date for incident transplant patients is obtained from the UNOS transplant dataset. Data from these sources is combined to establish the first ESRD service date (USRDS Researcher's Guide, 2005).

\section{Preemptive Kidney Transplantation}

If the time between the date of ESRD and transplantation was 6 months or less, then the transplant was considered to be preemptive. Otherwise, the transplant was nonpreemptive.

\section{Incidence and Prevalence}

Incidence is defined as the number of people in a population newly diagnosed with a disease in a given time period, typically a year, while prevalence is the number of people in a population who have the disease at a given point in time (point prevalence) or during a given time period (period prevalence). The USRDS generally reports point prevalence, which is the type of prevalence used primarily throughout the ADR as of December 31, 2005. Period prevalence is reported for a calendar year. Annual period prevalent data consist both of people who have the disease at the end of the year and those who had the disease during the 
year and died before the year's end. The USRDS treats successful transplantation as a therapy rather than as a "recovery" from ESRD. Patients transplanted at the time of ESRD initiation are counted as incident patients, while those with a functioning transplant are counted as prevalent. Because data are available only for patients whose ESRD therapy is reported to CMS, patients who die of ESRD before receiving treatment or whose therapy is not reported to CMS are not included in the database. The terms incidence and prevalence are thus qualified as incidence and prevalence of reported ESRD. Some ESRD registries, such as the European Dialysis and Transplantation Association, use the term "acceptance into ESRD therapy." The USRDS, however, believes that "incidence of reported ESRD therapy" is more precise, because "acceptance" implies that remaining patients are rejected, when in fact they may simply not be identified as ESRD cases or may not be reported to CMS. Point prevalence is a useful measure for public health research, since it measures the current burden of the disease on the health care delivery system, and period prevalence is appropriate for cost analysis, since it indicates the total disease burden over the course of the year. We have chosen, however, to focus primarily on the incidence of ESRD, believing that it is the most useful measure for medical and epidemiological research that examines disease causality and its effect on different sub-populations (USRDS Researcher's Guide, 2005).

\section{TRANSPLANT FAILURE}

It is generally assumed that the graft failure date reported in the UNOS Transplant Follow-up file or the REBUS Identification file is correct unless death or a new transplant occur before this date. It is possible, however, for a transplant failure date to go unrecorded 
in both files. In the absence of a transplant failure date, the USRDS derives the transplant failure date from the following sources:

- Date of death.

- Date of subsequent transplant.

- The date of return to regular dialysis, indicated by a continuous period of dialysis billing records covering a minimum of 60 days with at least 22 reported dialysis treatments.

- Date of return to dialysis reported on the Medical Evidence form, or the date of graft nephrectomy from either the UNOS transplant follow-up record or a Medicare claim.

- If no failure date is available, then the earliest of the above dates is used as the transplant failure date (USRDS Researcher's Guide, 2005). 


\section{CHAPTER 4. RESULTS}

This historical cohort study investigates whether there were inequities in the allocation of cadaver kidneys for preemptive kidney transplants (PKT) between blacks and whites. This issue is important because PKT has established itself as an attractive alternative to post dialysis conventional kidney transplantation (Asderakis, et al., 1998). PKT not only avoids the risks, costs, inconvenience and diminished quality of life of dialysis but has also been significantly associated with better graft and patient survival than transplantation after a period of dialysis. Numerous studies have provided convincing evidence that PKT is advantageous for patient and allograft survival (Mange and Weir, 2003). The significance to the patients, specifically blacks, of the under utilization of PKT and the overlooked opportunities for the avoidance of dialysis associated morbidities and improved graft and patient survival may be substantial. The research observation that whites and persons with higher incomes in the United States are more likely to be placed on the cadaveric waiting list before dialysis initiation and receive a PKT might suggest some systemic bias (Kasiske, et al., 2002). Examination of the 10,067 cadaver kidney transplant recipients that occurred between January 1, 2000 and December 31, 2003 allowed me to determine whether there was a disparity between blacks and whites with respect to the likelihood of their receiving cadaver kidneys for PKT.

This investigation used descriptive statistics and multivariate analyses to identify factors associated with whether a patient received a PKT or a conventional, post dialysis kidney transplant. Through the examination of the descriptive statistics, a comparison of the frequencies and percentages of PKT versus conventional post dialysis transplants between 
blacks versus whites was made. The multivariate analysis was used for the identification of factors associated with differences that may exist and also allowed for a determination of the statistical significance of any differences that may exist, after controlling for variables such as age, sex, employment, primary conditions leading to ESRD and health insurance. The conceptual framework (Fig. 3-2) guided the inclusion of variables used in the statistical analysis. The conceptual framework reflects the relationships among the variables linking the independent variable to the dependent variables and serves to clarify the research problem relating to the allocation of either preemptive or conventional cadaver kidneys. While the primary focus of this research was those transplant recipients who received a PKT, an overview of the ESRD population was provided, because the analysis of this population that allowed determinations as to whether the current system, policies and practices relating to the allocation of kidneys leads to an outcome that is proportionally reflective of the ESRD population.

The combination of the SAF, UNOS kidney transplant and the medical evidence form files resulted in a total of 1,600,693 CMS patient records (Fig. 4-1). From the aforementioned total, 1,513,366 of all CMS patients at least 19 years of age for the 4 year study period were designated as having ESRD. This group was made up of 459,746 (30.38\%) black and 1,053,620 (69.62\%) whites. Patients were designated as having ESRD when a physician certifies the disease on the medical evidence form (CMS 2728) or when there was other evidence that the person has received chronic dialysis or a kidney transplant.

Of the total number of patients being certified as having ESRD during the study period, 397,656 (92\%) did not receive a transplant. Noteworthy is the fact that 151,926 (38\%) of those not receiving a transplant died during the 4 year study period and only $4.5 \%$ 


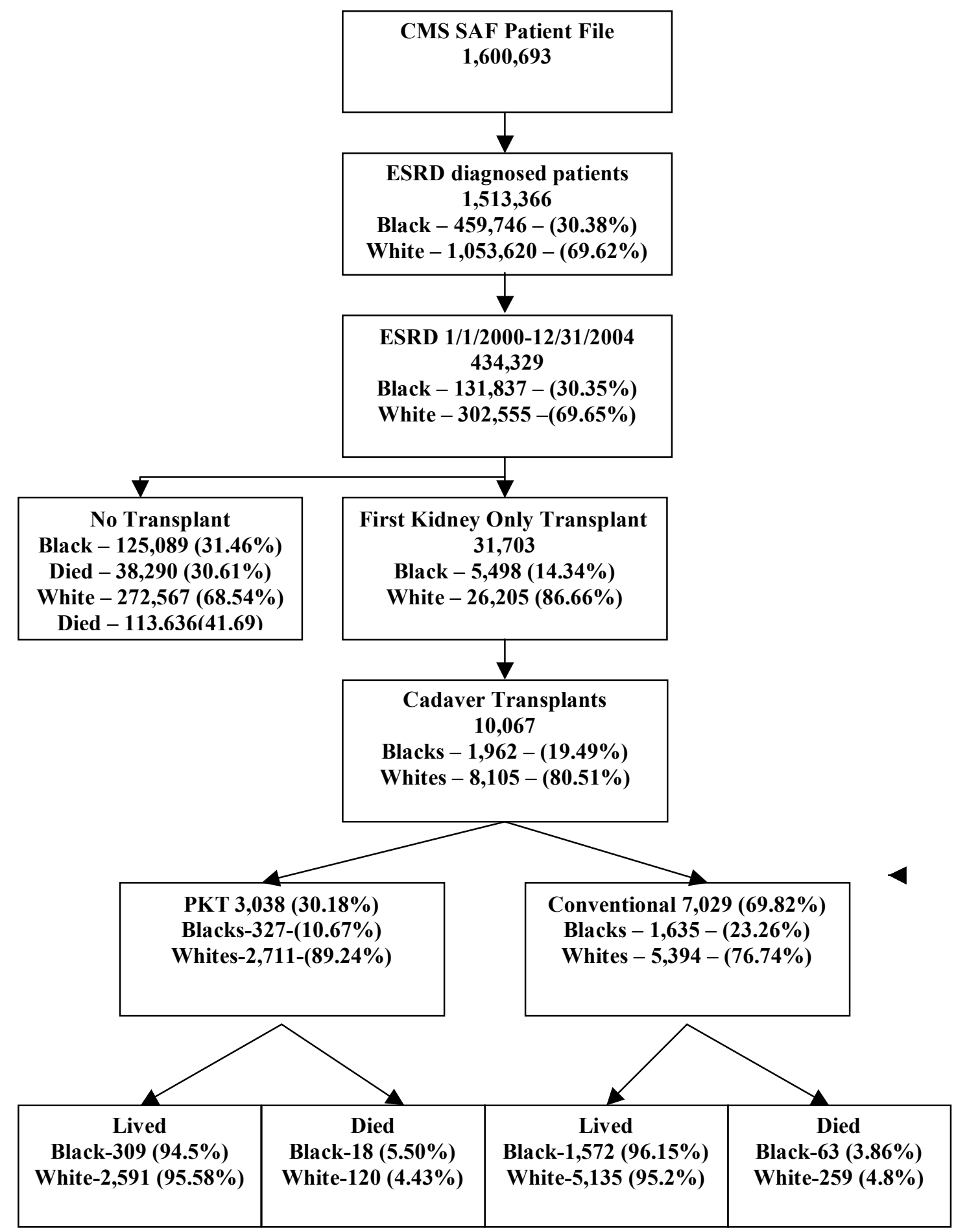

Figure 4-1. Flow chart of patients from entry into Center for Medicare Services System via standard analytical files through either PKT or conventional cadaver kidney transplant. 
of those receiving a transplant died. In the group of ESRD patients not receiving a transplant and dying during the study period $30.61 \%(38,290)$ were black and $41.69 \%(113,636)$ were white. A total of $245,730(61 \%)$ of those not receiving a transplant remained alive for the duration of the four year study period.

From the total of 434,329 black and white patients at least 19 years of age diagnosed with ESRD only 31,703 (7.45\%) patients received kidney transplants during the study period. Included in this total were recipients who received multiple transplants, living donor transplant recipients, cadaver donor transplant recipients, preemptive, and conventional transplant recipients. Of those in the ESRD population that received transplants only 5,498 (17.34\%) were black and 26,205 (83\%) were white.

Because the study period was from January 1, 2000 through December 31, 2003, ESRD patients who were either diagnosed or had their first dialysis or transplant before January 1, 2000, were excluded from this analysis. Patients who received a transplant subsequent to the conclusion of the study period, December 31, 2003 were also excluded. The total population of transplant recipients during the study period who were at least 19 years of age at the time of their first ESRD service during the study period and received their first time only either PKT or conventional cadaver transplant during the study period was $10,067(32 . \%)$ of the 32,703 kidney transplant recipients.

This isolated population of 10,067 cadaver transplant recipients was the sample subjected to further analysis for this investigation. This sample was comprised of 1,962 $(19.49 \%)$ black receiving cadaver transplants and 8,105 (80.51\%) whites. Of the blacks receiving cadaver transplants, $327(11 \%)$ received a PKT and 1,635(23\%) received 
conventional transplants. Among whites who received cadaver kidney transplants, 2,711(89\%) received a PKT and 5,394(75\%) received a conventional cadaver transplants.

As reflected in Table 4-1, the largest number of patients meeting study inclusion/exclusion criteria came from the 2000 cohort with decreasing numbers throughout the remaining years of the study period. Table 4-2, which shows the year and frequency of transplants performed reflects continued increases in the number of transplants that were performed annually. Explanations for both trends include simple increases in the number of conventional transplants as a result of individuals spending more time on the transplant waiting list and/or increases in the number of PKTs.

\section{REGION OF TRANSPLANT}

The transplant population examined in this investigation was distributed across the 11 organ procurement regions as defined by UNOS (Table 4-3). Most transplants took place in region 3 which was closely followed by region 2 . Region 3 led the country with most conventional transplants and was a close second in PKTs. Approximately $25 \%$ of the PKTs received by blacks occurred in organ procurement region 2 followed by over $20 \%$ of those residing in region 3 (Table 4-4). Blacks in region 2 received conventional kidney transplants at slightly lower rates, while whites received approximately the same rates of $14 \%$ for both PKT and conventional transplants in regions 2 and 3 respectively. The cautionary admonishment offered regarding the regional variations in cadaveric kidney transplant frequency reflected in Tables 4-3 and 4-4 is that it is dependent on many factors, including cadaveric organ availability, local competition for supply including ESRD prevalence, access to the transplant evaluation process, and the relative frequencies of donor-recipient pool 
Table 4-1. Year of first ESRD service for 10,067 patients included in the current cohort.

\begin{tabular}{ccc}
\hline & ESRD & \\
Year & Frequency & Cumulative Frequency \\
\hline 2000 & 4553 & 4553 \\
2001 & 3042 & 7595 \\
2002 & 1764 & 9359 \\
2003 & 708 & 10067 \\
\hline
\end{tabular}

Table 4-2. Year of transplant, frequency, percentage and cumulative frequency and percentage by year.

\begin{tabular}{ccccc}
\hline Year & Frequency & Percent & $\begin{array}{c}\text { Cumulative } \\
\text { Frequency }\end{array}$ & Cumulative Percent \\
\hline 2000 & 869 & 8.63 & 869 & 8.63 \\
2001 & 2045 & 20.31 & 2914 & 28.95 \\
2002 & 3379 & 33.57 & 6293 & 62.51 \\
2003 & 3774 & 37.49 & 10067 & 100 \\
\hline
\end{tabular}


Table 4-3. Frequency and percentage of PKT and conventional transplant recipients by region ${ }^{\text {b }}$.

\begin{tabular}{|c|c|c|c|c|}
\hline Region & $\begin{array}{c}\text { Total } \\
\text { Frequency }^{\mathrm{a}}\end{array}$ & $\begin{array}{c}\text { PKT } \\
\text { Frequency }\end{array}$ & $\begin{array}{l}\text { Conventional } \\
\text { Frequency }\end{array}$ & Percent $(\%)$ \\
\hline 1 & 391 & 86 & 305 & 3.92 \\
\hline 2 & 1468 & 448 & 1020 & 14.71 \\
\hline 3 & 1598 & 447 & 1151 & 16.10 \\
\hline 4 & 869 & 186 & 683 & 8.71 \\
\hline 5 & 1064 & 344 & 720 & 10.66 \\
\hline 6 & 412 & 115 & 297 & 4.13 \\
\hline 7 & 1070 & 406 & 664 & 10.72 \\
\hline 8 & 636 & 187 & 449 & 6.37 \\
\hline 9 & 476 & 155 & 321 & 4.77 \\
\hline 10 & 1014 & 284 & 730 & 10.16 \\
\hline 11 & 983 & 295 & 688 & 9.85 \\
\hline
\end{tabular}

a. $\quad$ Frequency missing $=86$

b. Region $1-\mathrm{CT}$, VT, ME, MA, NH, RI

Region 2 - DE, DC, MD, NJ, PA, WV

Region 3 - AL, AR, FL, GA, LA, MS, PR (U.S. Caribbean Islands and Virgin Islands)

Region 4 - TX, OK

Region 5 - AZ, CA, NV, NM, UT

Region 6 - AK, HI, ID, MT, OR, WA

Region 7 - IL, MN, ND, SD, WI

Region 8 - CO, IA, KS, MO, NE, WY

Region $9-\mathrm{NY}$

Region 10 - IN, MI, OH

Region $11-\mathrm{KY}, \mathrm{NC}, \mathrm{SC}, \mathrm{TN}, \mathrm{VA}$ 
Table 4-4. Frequency ${ }^{\mathrm{a}}$ and percentage of PKT and conventional kidney transplant recipients by region ${ }^{b}$ and by race.

\begin{tabular}{ccccc}
\hline & \multicolumn{2}{c}{ PKT } & \multicolumn{2}{c}{ Conventional } \\
\cline { 2 - 5 } Region & Black \% (n) & White \% (n) & Black \% (n) & White \% (n) \\
\hline 1 & $5(1.60)$ & $81(3.07)$ & $38(2.32)$ & $267(4.95)$ \\
2 & $80(25.64)$ & $368(13.93)$ & $289(17.68)$ & $731(13.55)$ \\
3 & $64(20.51)$ & $383(14.50)$ & $375(22.94)$ & $776(14.39)$ \\
4 & $10(3.21)$ & $176(6.66)$ & $161(9.85)$ & $522(9.68)$ \\
5 & $19(6.09)$ & $325(12.31)$ & $80(4.89)$ & $640(11.87)$ \\
6 & $2(0.64)$ & $113(4.28)$ & $22(1.35)$ & $275(5.10)$ \\
7 & $24(7.69)$ & $382(14.46)$ & $142(8.69)$ & $522(9.68)$ \\
8 & $8(2.56)$ & $179(6.78)$ & $57(3.49)$ & $392(7.27)$ \\
9 & $22(7.05)$ & $133(5.04)$ & $79(4.83)$ & $242(4.49)$ \\
10 & $36(11.54)$ & $248(9.39)$ & $171(10.46)$ & $559(10.37)$ \\
11 & $42(13.46)$ & $253(9.58)$ & $221(13.52)$ & $467(8.66)$ \\
\hline Total & $\mathbf{3 1 2}$ & $\mathbf{2 , 6 4 1}$ & $\mathbf{1 , 6 3 5}$ & $\mathbf{5 , 3 9 3}$
\end{tabular}

a. Frequency missing $=86$ due to missing data

b Region 1 - CT, VT, ME, MA, NH., RI

Region 2 - DE., DC, MD., NJ, PA., WV

Region 3 - AL, AR., FL, GA, LA, MS, PR (U.S. Caribbean Islands and Virgin Islands)

Region 4 - TX, OK

Region 5 - AZ, CA, NV, NM, UT

Region 6 - AK, HI, ID, MT, OR, WA

Region 7 - IL, MN, ND, SD, WI

Region 8 - CO, IA, KS, MO, NE, WY

Region $9-\mathrm{NY}$

Region 10 - IN, MI, OH

Region 11 - KY, NC, SC, TN, VA 
biologic incompatibilities that may affect status on a given match-run Nonetheless, the existence of these variations, whether they are real or apparent, suggests that the allocation of organs for transplantation in the United States is not uniform across all regions.

\section{CHARACTERISTICS OF PREEMPTIVE AND CONVENTIONAL TRANSPLANT RECIPIENTS}

Over a period of four years, January 1, 2000 through December 31, 2003, a total of 10,067 patients experienced ESRD and received primary kidney-only cadaver donor transplants. Overall, 30.18\% (3,038) of these 10,067 transplants were PKT (Table 4-5). The remaining $69.82 \%(7,029)$ make up the conventional kidney transplant group of patients who were transplanted after having been treated by hemodialysis or continuous ambulatory peritoneal dialysis (CAPD) for six months or longer. Blacks accounted for $10.76 \%$ (327) of the PKT recipients and $23.26 \%$ (1635) of the conventional transplants, with an overall rate of $19.49 \%$ (1962) of the 10,067 patients who received cadaver transplants. Whites accounted for $89.24 \%(2,711)$ of the PKT group and $76.74 \%$ of the conventional transplant group.

Overall, whites accounted for $80.51 \%$ of the patients who received cadaver transplants during

Table 4-5. Frequency of PKT and conventional transplants occurring between January 1, 2000 and December 31, 2003 among patients who developed ESRD during the same time period, according to gender and race.

\begin{tabular}{|c|c|c|c|c|c|}
\hline & \multicolumn{2}{|c|}{ PKT } & \multicolumn{2}{|c|}{ Conventional } & Total \\
\hline & $\begin{array}{l}\text { Black } \\
327(10.76 \%)\end{array}$ & $\begin{array}{l}\text { White } \\
2711(89.24 \%)\end{array}$ & $\begin{array}{l}\text { Black } \\
1635(23.26 \%)\end{array}$ & $\begin{array}{l}\text { White } \\
5394(76.74 \%)\end{array}$ & \\
\hline Male & 56.27 & 57.62 & 59.69 & 63.27 & $57.47 \%$ \\
\hline Female & 43.73 & 42.38 & 40.31 & 36.73 & $42.53 \%$ \\
\hline Total & 3038 & $0.18 \%)$ & 729( & $9.82 \%)$ & 10,067 \\
\hline
\end{tabular}


the study period. Overall, males $(57.47 \%)$ received preemptive kidney transplants more frequently than females $(42.53 \%)$. Likewise, more males received conventional transplants $(62.44 \%)$ than females $(37.56 \%)$.

\section{Age}

The mean age for all black transplant recipients in this cohort was 47.7 years of age compared to 49.8 years of age for white transplant recipients across all groups. For all PKT recipients the mean age was 49.1 years compared with a mean age of 48.4 years for all conventional transplant recipients. Black PKT recipients had a mean age of 48.4 years of age (Table 4-6) while their white PKT counterparts were almost a year older at 49.8 years of age, indicating that, for blacks who did receive a PKT, they did so at a younger age, on average, than did their white counterparts. Black conventional transplant recipients at an average of 47 years of age were also younger than their white conventional transplant recipient peers. Overall, blacks received transplants at younger ages than whites. Across all groups, transplants were more likely among recipients aged 40 through 64 (Table 4-7). At least 1 black PKT patient was over 77 years of age and 3 white PKT patients were over 82 years of age at the time of their transplant. There was at least 1 black transplant recipient who received a conventional kidney transplant at 79 years of age and at least 5 white transplant recipients who were over 82 years old at the time of their transplant.

\section{Employment}

PKT recipients were more likely than conventional kidney transplant recipients to be employed full-time (Table 4-8). It is not difficult to understand that patients who are not yet 
Table 4-6. Mean age in years of patients by race receiving either a PKT or conventional kidney transplant between January 1, 2000 and December 31, 2003.

\begin{tabular}{ccccc}
\hline $\begin{array}{c}\text { Transplant } \\
\text { Type }\end{array}$ & & $\mathrm{N}$ & Mean $(\mathrm{yr})$ & Std. Error (yr) \\
\hline Preemptive & Black & 327 & 48.4 & 0.69 \\
& White & 2711 & 49.8 & 0.23 \\
Conventional & & & & \\
& Black & 1635 & 47.0 & 0.31 \\
& White & 5394 & 49.9 & 0.17 \\
\hline Total & & 10,067 & & \\
\hline
\end{tabular}

Table 4-7. Age category at first ESRD service and kidney transplant frequency included in the current cohort.

\begin{tabular}{ccc}
\hline Age Category & Frequency & Percent $(\%)$ \\
\hline 19 & 43 & 0.43 \\
$20-24$ & 272 & 2.70 \\
$25-29$ & 467 & 4.64 \\
$30-34$ & 731 & 7.26 \\
$35-39$ & 888 & 8.82 \\
$40-44$ & 1123 & 11.16 \\
$45-49$ & 1441 & 14.31 \\
$50-54$ & 1541 & 15.31 \\
$55-59$ & 1350 & 13.41 \\
$60-64$ & 1102 & 10.95 \\
$65-69$ & 734 & 7.29 \\
$70-74$ & 290 & 2.88 \\
$75-79$ & 76 & 0.75 \\
$80-84$ & 9 & 0.09 \\
\hline
\end{tabular}


Table 4-8. Employment status in percentages of PKT and conventional transplant recipients by race.

\begin{tabular}{ccccc}
\hline & \multicolumn{2}{c}{ PKT } & \multicolumn{2}{c}{ Conventional } \\
\cline { 2 - 5 } $\begin{array}{c}\text { Current } \\
\text { Employment } \\
\text { Status }\end{array}$ & $\begin{array}{c}\text { Black } \\
(\mathrm{n}=226)\end{array}$ & $\begin{array}{c}\text { White } \\
(\mathrm{n}=2,037)\end{array}$ & $\begin{array}{c}\text { Black } \\
(\mathrm{n}=1,541)\end{array}$ & $\begin{array}{c}\text { White } \\
(\mathrm{n}=5,127)\end{array}$ \\
\hline Unemployed & $42(18.58)$ & $337(16.54)$ & $397(25.76)$ & $878(17.13)$ \\
Employed & & & & \\
Full-Time & $79(34.96)$ & $756(37.11)$ & $441(28.62)$ & $1,566(30.54)$ \\
Employed & & & & \\
Part-Time & $4(1.77)$ & $114(5.60)$ & $54(3.50)$ & $232(4.53)$ \\
Homemaker & $3(1.33)$ & $96(4.71)$ & $31(2.01)$ & $236(4.60)$ \\
Ret-Age & $25(11.06)$ & $234(11.49)$ & $158(10.25)$ & $740(14.43)$ \\
Ret-Disab & $43(19.03)$ & $321(15.76)$ & $305(19.79)$ & $1,055(20.58)$ \\
Med LOA & $24(10.62)$ & $166(8.15)$ & $137(8.89)$ & $380(7.41)$ \\
Student & $6(2.65)$ & $13(0.64)$ & $18(1.17)$ & $40(0.78)$
\end{tabular}


on dialysis may be better able to work full-time, because dialysis can make it difficult to maintain full-time employment. Another potential advantage of PKT may be allowing at least some individuals to continue to work. White PKT recipients were more likely to be employed full-time at $37.11 \%$ (756) compared to $34.96 \%$ (79) for blacks. Black PKT patients were slightly more likely to report being unemployed at $18.58 \%$ (42) when compared to white PKT recipients at 16.54\% (337). White PKT recipients also reported higher rates of part-time employment 5.60\% (114), being homemakers $4.71 \%$ (96), and being retired at $11.49 \%$ (234) than did black PKT recipients. Black patients did have higher percentages of retired disabled at $19.03 \%$ (43), those on medical leave of absence at $10.62 \%$ (24) and students at 2.65\% (6). Black conventional kidney transplant recipients reported being unemployed at a rate much higher than that of white conventional transplant recipients $25.76 \%$ (397) compared to $17.13 \%$ (878) for whites. Whites reported higher rates of

employment, 30.54\% (1566), part-time employment, 4.53\% (232), being homemakers, $4.60 \%$ (236), being of retirement age, $14.43 \%$ (740), and retirement disabled at $20.58 \%$ (1055) and students at $1.17 \%$. For black conventional kidney transplant recipients unemployment, $25.76 \%$ and those on a medical leave of absence, $8.89 \%$, were the only categories in which the percentages of blacks exceeded those of whites. There were not any differences in employment status between blacks and whites for either PKT or conventional recipients.

\section{CAUSES OF ESRD}

Overall, the leading cause of ESRD for this cohort was diabetes, followed by hypertension (renal disease caused by hypertension with no primary renal disease), 
glomerulonephritis, and cystic kidney disease (Table 4-9). In the black PKT population, the causes listed as leading to ESRD were diabetes $21.71 \%$ (71) and hypertension $19.88 \%$ (65) and for black conventional kidney transplant recipients both diabetes $34.43 \%$ (563) and hypertension $32.42 \%$ (563) remained the leading causes of ESRD. In white PKT patients the leading causes of their ESRD were diabetes at 30.51\% (827), glomerulonephritis $13.32 \%$ (361), and cystic kidney disease 13.24\% (359). In white PKT patients hypertension was listed as the cause of ESRD for only 7.49\% (203) of the recipients. For white conventional transplant recipients diabetes remained the dominant cause of ESRD at 39.19\% (2114) with glomerulonephritis remaining second at $20.47 \%$ (1104). There were differences between the PKT recipients and the conventional transplant recipients across the 3 major causes of ESRD, diabetes, hypertension and glomerulonephritis.

\section{KIDNEY DONOR RACE}

Overall 89.24\% ( $\mathrm{n}=2,711)$ of the donor kidneys received by PKT recipients and $76.74 \%(n=5,394)$ of those received by conventional transplant recipients were obtained from white cadaver donors (Table 4-10). Black PKT patients received 69.42\% $(n=227)$ of their kidneys from white donors and 17.43\% (57) from blacks. White PKT patients received $5.94 \%$ (161) from black donors with the bulk of their PKT donations $(77.61 \%(n=2,104)$ coming from other white donors. Among the 1,635 black conventional transplant recipients, $16.39 \%(\mathrm{n}=268)$ of the kidneys came from black donors and $68.87 \%(\mathrm{n}=1,126)$ came from white donors. Black donors were responsible for $5.82 \%(n=314)$ of the organ donations to whites, with other whites contributing $77.29 \%(n=4,169)$. More black cadaver donor kidneys were transplanted into whites than into black kidney recipients. Thus despite a greater 
Table 4-9. Primary disease causes of ESRD in frequency and percentages of PKT and conventional kidney transplant recipient, by race.

\begin{tabular}{lllll}
\hline & \multicolumn{2}{c}{ PKT } & \multicolumn{2}{c}{ Conventional } \\
\cline { 2 - 5 } \multicolumn{1}{c}{ Primary Disease } & Black & & White \\
Category & $\mathrm{n}=327$ & White & Black & $\begin{array}{l}\mathrm{n}=5,394 \\
\mathrm{n}=2,711(89.24)\end{array}$ \\
\hline Diabetes & $(10.76)$ & $827(30.51)$ & $563(34.43)$ & $2,114(39.19)$ \\
Hypertension & $65(19.88)$ & $203(7.49)$ & $530(32.42)$ & $699(12.96)$ \\
Glomerulonephritis & $45(13.76)$ & $361(13.32)$ & $301(18.41)$ & $1,104(20.47)$ \\
Cystic Kidney & $21(6.42)$ & $359(13.24)$ & $56(3.43)$ & $662(12.27)$ \\
Other Urologic & $20(6.12)$ & $130(4.80)$ & $18(1.10)$ & $153(2.84)$ \\
Other cause & $32(9.79)$ & $351(12.95)$ & $98(5.99)$ & $482(8.94)$ \\
Unknown Cause & $15(4.59)$ & $148(5.46)$ & $67(4.10)$ & $179(3.32)$ \\
Missing Cause & $58(17.74)$ & $332(12.25)$ & $2(0.12)$ & $1(0.02)$ \\
\hline
\end{tabular}

Table 4-10. Kidney donor race in frequency and percentages of PKT and conventional kidney only transplant recipients.

\begin{tabular}{ccccc}
\hline & \multicolumn{2}{c}{ PKT } & \multicolumn{2}{c}{ Conventional } \\
\cline { 2 - 5 } & Black & White & Black & White \\
Donor Race & $(\mathrm{n}=218)$ & $(\mathrm{n}=2,331)$ & $(\mathrm{n}=582)$ & $(\mathrm{n}=5,295)$ \\
Asian & $4(1.22)$ & $31(1.14)$ & $19(1.16)$ & $72(1.33)$ \\
Black & $57(17.43)$ & $161(5.94)$ & $268(16.39)$ & $314(5.82)$ \\
White & $227(69.42)$ & $2,104(77.61)$ & $1,126(68.87)$ & $4,169(77.29)$ \\
Other/Unknown & $39(11.93)$ & $394(14.86)$ & $221(13.52)$ & $823(15.26)$ \\
\hline
\end{tabular}


percentage of the kidneys from black donors being transplanted into white recipients, the overwhelming majority of the available organs were obtained from white donors.

\section{PATIENT OUTCOMES FOR PKT AND CONVENTIONAL KIDNEY TRANSPLANT RECIPIENTS}

The association among race, PKT, conventional kidney transplantation, and outcomes were analyzed based on four measures assessed on December 31, 2003: alive with functioning graft, alive without functioning graft, died with a functioning graft and died after graft loss (Table 4-11). Among black recipients those alive with functioning grafts from either PKT or conventional transplants, were $81.65 \%$ and $84.04 \%$, respectively. There was a slightly higher percentage of black conventional kidney transplant recipients alive with functioning grafts than there were PKT recipients. For those alive without functioning grafts blacks had approximately $12 \%$ of both PKT and conventional kidney transplant recipients. Fewer blacks with a PKT died after graft loss, $0.92 \%$ than did conventional kidney transplant recipients with $1.35 \%$. However, the percentage of PKT blacks that died with a functioning graft, $4.59 \%$, was more than that of blacks with conventional kidney transplants $(2.51 \%)$.

As was the case with blacks, whites with conventional kidney transplants had a slightly better percentage of those surviving with a functioning graft than did the PKT recipients. More PKT whites survived with graft loss than did white conventional kidney transplant recipients but fewer white PKT recipients died after graft loss $(0.63 \%)$ than did conventional kidney transplant recipients (1.11\%). A slightly larger percentage of white PKT recipients died with a functioning graft (3.80\%) than did white conventional kidney transplant recipients $(3.69 \%)$. 
Table 4-11. Percentages and frequencies for various outcomes for patients receiving a PKT or conventional transplant ${ }^{\mathrm{a}}$.

\begin{tabular}{|c|c|c|c|c|}
\hline \multirow[b]{2}{*}{ Outcome } & \multicolumn{2}{|c|}{$\mathrm{PKT}^{\mathrm{b}}$} & \multicolumn{2}{|c|}{ Conventional $^{\mathrm{c}}$} \\
\hline & $\begin{array}{l}\text { Black } \\
(n=327)\end{array}$ & $\begin{array}{l}\text { White } \\
(\mathrm{n}=2711)\end{array}$ & $\begin{array}{l}\text { Black } \\
(n=1635)\end{array}$ & $\begin{array}{l}\text { White } \\
(\mathrm{n}=5394)\end{array}$ \\
\hline $\begin{array}{l}\text { Alive with } \\
\text { functioning graft }\end{array}$ & $267(81.65)$ & $2,356(86.91)$ & $1,374(84.04)$ & $4,722(87.54)$ \\
\hline $\begin{array}{l}\text { Alive with graft } \\
\text { loss }\end{array}$ & $42(12.84)$ & $235(8.67)$ & $198(12.11)$ & $413(7.66)$ \\
\hline Died after graft loss & $3(0.92)$ & $17(0.63)$ & $22(1.35)$ & $60(1.11)$ \\
\hline $\begin{array}{l}\text { Died with } \\
\text { functioning graft }\end{array}$ & $15(4.59)$ & $103(3.80)$ & $41(2.51)$ & $199(3.69)$ \\
\hline
\end{tabular}

a. The cohort consisted of all patients who experienced ESRD and/or received a cadaver kidney transplant between January 1, 2000 and December 31, 2003.

b. No significant difference was detected between blacks and whites with respect to the 4 outcome groups $(\mathrm{p}<.0615)$.

c. A significant difference was detected between blacks and whites with respect to the 4 outcome groups $(\mathrm{p}<.0001)$. 
A larger proportion of white PKT recipients (86.9\%) lived with functioning grafts compared to black PKT transplant recipients (81.65\%); however, a larger proportion of black PKT recipients were alive after graft loss (12.84\%) compared to white PKT recipients (12.11\%). A smaller proportion of white PKT recipients died after graft loss $(0.63 \%)$ than black PKT recipients $(0.92 \%)$. A larger proportion of blacks PKT recipients died with a functioning graft (4.59\%) than did white (3.80\%) PKT recipients. Outcomes for white conventional kidney transplant recipients were similar to those of the PKT group with the marked exception of those who died with a functioning graft. White conventional kidney transplant recipients died with greater frequency (3.69\%) when compared to blacks conventional transplant recipients $(2.51 \%)$.

\section{TIME TO TRANSPLANTATION}

For the 327 black PKT recipients the median elapsed time from first service for dialysis to transplantation was 1 day (mean \pm se: $1.0894 \pm 0.0966$ months) compared to black conventional transplant recipients whose median elapsed time was 22.47 months (mean \pm se: $23.2178 \pm 0.25$ months). The mean time for the 2711 white PKT recipients was, as it was with the PKT blacks, 1 day (mean \pm se: $1.0941 \pm 0.0342$ months). White conventional kidney transplant recipients had a median elapsed time of 18.29 months (mean $\pm 19.7203 \pm$ 0.1261 months) (Table 4-12). Although black and white PKT recipients both had a median elapsed time of 1 day as their elapsed time from first service for dialysis and their kidney transplant, there was a difference of approximately 4 months waiting time between blacks and whites receiving conventional kidney transplants. 
Table 4-12. Racial disparity in elapsed time from first service for dialysis and transplantation.

\begin{tabular}{cccccc}
\hline $\begin{array}{c}\text { Type } \\
\text { Transplant }\end{array}$ & Race & $\begin{array}{c}\text { No. of } \\
\text { Patients }\end{array}$ & Mean (Mo) & $\begin{array}{c}\text { Median } \\
(\text { Mo })\end{array}$ & $\begin{array}{c}\text { Std. Error } \\
\text { (Mo) }\end{array}$ \\
\hline Preemptive & & & & & \\
& Black & 327 & 1.09 & 0.032 & 0.09 \\
& White & 2711 & 1.09 & 0.32 & 0.03 \\
Conventional & & & & & \\
& Black & 1635 & 23.21 & 22.47 & 0.24 \\
& White & 5394 & 19.72 & 18.29 & 0.12 \\
\hline
\end{tabular}

\section{MULTIVARIATE ANALYSIS}

For all cadaver transplant recipients in the study cohort, the odds of receiving a preemptive kidney transplant were 2.5 times greater for whites than for blacks (Table 4-13). This result was statistically significant. For this same cohort the odds of receiving a preemptive kidney transplant were $23 \%$ greater for females compared with males. This result was also statistically significant. Compared with those patients who had a diagnosis of hypertension as the primary cause for their ESRD, a patient was more than twice as likely to receive a preemptive transplant if they had a diagnosis that indicated that their ESRD was primarily caused by something other than hypertension. Compared to patients who had a diagnosis of diabetes as the primary cause of their ESRD, those who did not have that diagnosis had a $46 \%$ greater likelihood of getting a preemptive kidney transplant. Compared with patients who had a diagnosis of glomerulonephritis as the primary cause of their ESRD those patients who did not have that diagnosis had a $62 \%$ greater likelihood of getting a preemptive kidney transplant. 
Table 4-13. Recipient characteristics associated with preemptive kidney transplantation ${ }^{\mathrm{a}}$.

\begin{tabular}{cccc}
\hline Variable & Reference Group & $\begin{array}{c}\text { Odds Ratio } \\
(95 \% \mathrm{CI})\end{array}$ & P value \\
\hline Black & White & 0.3979 & $<0.0001$ \\
Female & Male & $(0.35$ to 0.45$)$ & \\
& 1.230 & $<0.0016$ \\
Not-Hypertension & Hypertension $^{\mathrm{b}}$ & $(1.12$ to 1.34$)$ & \\
& 2.190 & $<0.0001$ \\
Not-Diabetes & Diabetes $^{\mathrm{b}}$ & $(1.90$ to 2.51$)$ & \\
& & 1.465 & $<0.0001$ \\
Not- & Glomerulonephritis $^{\mathrm{b}}$ & $(1.33$ to 1.60$)$ & \\
Glomerulonephritis & & $(1.619$ & $<0.0001$ \\
\end{tabular}

a. Odds rations and confidence limits were estimated from $2 \times 2$ contingency tables.

b. As the cause of ESRD.

Although the analysis reflected in Table 4-13 shows race and other variables are significantly related to receiving a PKT, the analysis must be carried further to demonstrate a disparity. These differences reflected at this point do not demonstrate a disparity between blacks and whites in the rates in which they receive PKTs. In a broad context, we think of health disparities as the population specific differences in the presence of disease, health outcomes or access to health care. Health Disparities, as defined by the Institute of Medicine's Committee on Understanding and Eliminating Racial and Ethnic Disparities in Health Care, are racial and ethnic differences in the quality of health care that are not due to access-related factors or clinical needs, preferences, or appropriateness of the intervention (IOM, 2003).

Although every member in the cohort had access to Medicare they all did not use Medicare for their ESRD treatment and/or transplant. All insurance is not the same insurance. That is to say that all insurance does not afford the same level of access. 
Therefore to determine if there was a true disparity between blacks and whites in PKT it is necessary to control for access in order to balance the variables that may give one group an advantage over the other in access to PKT. To do so, a subset of the cohort ( $\mathrm{n}=847)$ - only those utilizing Medicare Parts A and B-was subjected to the multivariate analysis in order determine if the significance of the aforementioned variables goes further to demonstrate that there was actually a disparity between blacks and whites relative to receipt of PKT (Table 4-14). As reflected in Table 4-14 race and the aforementioned comorbid conditions of hypertension, diabetes, and glomerulonephritis remained statistically significant, similar to the findings reported in Table 4-13. For those in the subset cohort, the odds of receiving a preemptive kidney transplant were almost $60 \%$ less likely for blacks than for whites (Table 4-14). Those in this subset cohort had $15 \%$ greater odds for a PKT if they were females compared to males, which was a lower odds ratio than in the overall cohort. Compared with those patients who had a diagnosis of hypertension, diabetes or glomerulonephritis as the primary cause for their ESRD a patient had $80 \%, 50 \%$, and $24 \%$ respectively greater odds of getting a preemptive transplant if they had a diagnosis that indicated that one of these was not the primary cause of their ESRD.

A second strategy was used to again control for the role of access in PKT receipt. The full cohort was subjected to a final expanded multivariate analysis, which included two insurance variables - those with Medicare, both parts A and B - and those with Medicare as the secondary payer (Table 4-15). The employment variable was also included in this analysis to test for its effect on the likelihood of receiving a PKT. These results remained consistent with the previous two analyses (Tables 4-13 and 4-14) with race, hypertension, 
Table 4-14. Medicare A and B only recipient characteristics associated with preemptive kidney transplantation.

\begin{tabular}{cccc}
\hline Variable & $\begin{array}{c}\text { Reference } \\
\text { Group }\end{array}$ & $\begin{array}{c}\text { Odds Ratio } \\
(95 \% \text { CI })\end{array}$ & P value \\
\hline Age 40 to 55 & Age $>55$ & 1.000 & 0.9508 \\
Black & White & $(0.989$ to 1.010$)$ & 0.4294 \\
Female & Male & $(0.2945$ to 0.6261$)$ & 0.0002 \\
& & 1.1474 & 0.5322 \\
Non-Hypertension & Hypertension & $(0.8671$ to 1.5184$)$ & \\
Non-Diabetes & Diabetes & $(1.2095$ to 2.6973$)$ & $<.0001$ \\
& & 1.4976 & $<.0001$ \\
Non- & Glomerulonephritis & $(1.1177$ to 2.0065$)$ & \\
Glomerulonephritis & & 1.2415 & 0.0002 \\
\hline
\end{tabular}

Table 4-15. Recipient characteristics associated with a preemptive kidney transplantation with employment and Medicare $A$ and $B$ as primary payer and/or Medicare as a secondary payer included in the model.

\begin{tabular}{|c|c|c|c|}
\hline Variable & $\begin{array}{l}\text { Reference } \\
\text { Group }\end{array}$ & $\begin{array}{l}\text { Odds Ratio } \\
(95 \% \mathrm{CI})\end{array}$ & $\mathrm{P}$ value \\
\hline Age 40 to 55 & Age $>55$ & $\begin{array}{c}0.999 \\
(0.995 \text { to } 1.003)\end{array}$ & 0.0122 \\
\hline Black & White & $\begin{array}{c}0.460 \\
(0.403 \text { to } 0.526)\end{array}$ & $<.0001$ \\
\hline Female & Male & $\begin{array}{c}1.142 \\
(1.042 \text { to } 1.252\end{array}$ & 0.0044 \\
\hline Not-Hypertension & Hypertension & $\begin{array}{c}3.003 \\
(2.598 \text { to } 3.541)\end{array}$ & $<.0001$ \\
\hline Not-Diabetes & Diabetes & $\begin{array}{c}2.354 \\
(2.120 \text { to } 2.615\end{array}$ & $<.0001$ \\
\hline $\begin{array}{l}\text { Not- } \\
\text { Glomerulonephritis }\end{array}$ & Glomerulonephritis & $\begin{array}{c}2.733 \\
(2.391 \text { to } 3.125)\end{array}$ & $<.0001$ \\
\hline Employed & Not-Employed & $\begin{array}{c}1.133 \\
(1.024 \text { to } 1.254)\end{array}$ & 0.0153 \\
\hline HMO and other & $\begin{array}{c}\text { Medicare A and B } \\
\text { only }\end{array}$ & $\begin{array}{c}2.204 \\
(1.966 \text { to } 2.471)\end{array}$ & $<.0001$ \\
\hline HMO and other & Medicare Secondary & $\begin{array}{c}1.800 \\
\text { (1.610 to } 2.013)\end{array}$ & $<.0001$ \\
\hline
\end{tabular}


diabetes and glomerulonephritis, reflecting the statistically significant relationships they had with PKT in the two aforementioned analyses. Employment did not show a statistically significant relationship and appears to have no direct effect on whether blacks or whites receive PKT. However, insurance, both Medicare A and B and Medicare as a secondary payer did show statistical significance. The interpretation of the statistical significance of insurance is that those not covered by Medicare A and B are almost more than twice as likely to receive a PKT as those covered by Medicare A and B. Those not covered by Medicare as a secondary payer were more than $80 \%$ more likely to receive a PKT as those covered by Medicare A and B. This finding is supported in reflecting back on the subset used to develop the cohort analyzed in Table 4-14. There were only 847 patients identified from the overall cohort of 10,067 (8.4\%) identified as those on Medicare A and B insurance. Of those 847 patients identified in the subset there were 43 black PKT recipients which constituted 5.08\% of those on Medicare A and B only, but .03\% of the overall cohort.

When these five independent predictors of receiving a PKT in the analysis of the full cohort, (Table 4-14) were included: black race ( $[\mathrm{OR}]=0.46$, reference: white, i.e., whites $46 \%$ greater odds to receive a PKT than blacks); female ( $\mathrm{OR}=1.16$ reference: male; i.e., females $16 \%$ more likely to receive a preemptive kidney transplant than males); nonhypertensive ( $\mathrm{OR}=3.25$, reference: hypertension) those without hypertension as the primary cause of ESRD were more than 3 times more likely to receive a PKT); non-diabetics ( $\mathrm{OR}=$ 2.45, reference: diabetes), those without diabetes as the primary cause of ESRD were more than 2 time more likely to receive a PKT; non-glomerulonephritis $(\mathrm{OR}=2.82$; reference: Glomerulonephritis, those without glomerulonephritis as the primary cause of ESRD were more than 2 times more likely to receive a PKT). 
Subsequent analysis limiting the scope to a subset of the overall cohort to those who had Medicare A and B insurance (Table 4-14) only produced similar results to the analysis of the overall cohort. Race, diabetes, hypertension and glomerulonephristis remained statistically significant. A final analysis of the overall cohort that also included employment and Medicare A and B as the primary insurance and those who had Medicare as a secondary payer (Table 4-15) also produced similar results in that race remained significant as did diabetes, hypertension and glomerulonephritis. Employment, was also statistically significant in its relationship or a predictor of whether someone receives a PKT. Medicare A and B as the primary insurance and those who had Medicare as a secondary payer each did reflect statistical significance as indicators of being less likely for those patients with Medicare A and B and/or those patients with Medicare as a secondary insurance to receive a PKT.

The overall hypothesis of this research is that the distribution of PKT is not equitable and this inequity is to the detriment of blacks. First, as this research points out there are clear differences between blacks and whites in PKT rates. Secondly and most importantly this research demonstrates that not only are there differences but that a true disparity exist in the allocation of PKT between blacks and whites. Thus this research indicates that the leading causes of ESRD in blacks and whites who received PKTs was diabetes (22\%) and (31\%) respectively. Black conventional transplant recipients had higher rates of hypertension and diabetes than did black PKT recipients overall. White conventional kidney transplant recipients had the highest rates of diabetes (39.19\%) of all groups. Of all PKT recipients blacks received $10.76 \%$ compared to $89.24 \%$ received by whites. The mean age for blacks receiving PKTs was 48.4 years of age compared to 47 years of age for black conventional 
kidney transplant recipients. The mean age for whites, both PKT and conventional transplant recipients was approximately 49 years of age. Higher percentages of PKTs took place in the northeastern and southeastern regions (UNOS regions 2 and 3) of the United States. The majority of PKT recipients (both blacks and whites) received their donor organs from whites. Blacks received $69.42 \%$ white donor organs compared to $77.61 \%$ received by whites. Blacks did receive $17.43 \%$ of their donor organs from blacks, with whites receiving approximately $6 \%$ of their organs from blacks. For those receiving PKTs during the study period, $86 \%$ of whites and $81 \%$ of blacks were alive with functioning grafts. 


\section{CHAPTER 5. CONCLUSION}

There remain unexplained differences between blacks and whites in receiving both PKT and non-PKT. It has been suggested that these differences may be the result of institutional racism. Indeed the Institute of Medicine concluded in its recent report on the racial and ethnic disparities in health care that "although a myriad sources contribute to these disparities, some evidence suggests that bias, prejudice, and stereotyping on the part of health care providers may contribute to differences in care" (IOM, 2002).

From this analysis it is concluded that a disparity does exist in the allocation of PKTs between blacks and whites. This research advances this body of literature in that it narrows the scope of the 2002 work of Kasiske, et al. to focus on cadaver donor kidneys, which exposes the vulnerabilities of the UNOS waiting list in its roll in the allocation of cadaver donor kidneys and at the same time serves to highlight the problems with the kidney evaluation process. Most importantly, this research serves to clearly articulate the disparity between blacks and whites in the allocation of PKTs. Above and beyond other research that included both living and cadaver kidneys in their analysis, this research focused on cadavers only and instead of limiting the scope to pointing out difference and odds ratio relating to those differences in this research access was controlled for by limiting the analysis to those with Medicare A and B only and still being able to identify the statistical significance of race. This analysis, by controlling for access, was able to state emphatically that there is disparity in the allocation of PKT between blacks and whites. This disparity reflects an inequality in the allocation of cadaver kidneys. 
In the United States, we believe that health care should be fairly distributed by race, ethnicity, socioeconomic status, or geographic location. When unfair differences exist, they are referred to as disparities. It is important to understand that differences in race and ethnicity will always exist; it is wrong, however, when these differences lead to unequal care. The specter of health disparities represents an egregious failure of the medical community in the United States (Young \& Kew, 2005). Despite the unprecedented explosion in scientific knowledge relating to kidney transplantation and the phenomenal capacity of the transplant process and the immunosuppression medications to balance the matching issues related to kidney transplants, blacks have not benefited fully or equitably from the fruits of this science or from those systems responsible for the equitable allocation of cadaver kidneys. Despite the efforts here and in other research, the reasons for the disparities in both PKT and conventional kidney transplant recipients are not fully understood. It is likely, however, that the complete picture incorporates a complex interaction between socio-cultural, genetic, and environmental factors. As reflected in Fig. 5-1, the IOM (2003) identifies the operation of the health care system, the legal and regulatory climate in which health care takes place, and/or the biases and prejudices that come with discrimination, prejudice, and stereotyping, and factors that may contribute to the disparities reflected in PKT and other health care dynamics.

In this country, blacks are much less likely than whites to be referred to nephrologists and undergo renal transplantation in a timely manner (Kausz, et al., 2000). Race has historically been a factor that is reflected in the literature as having an influence on access to general health care in the United States. Non-minorities enjoy a better quality of health care than do minorities. In trying to understand disparities a spectrum of possibilities offers possible explanations. Disparities between minorities and non-minorities may be the 


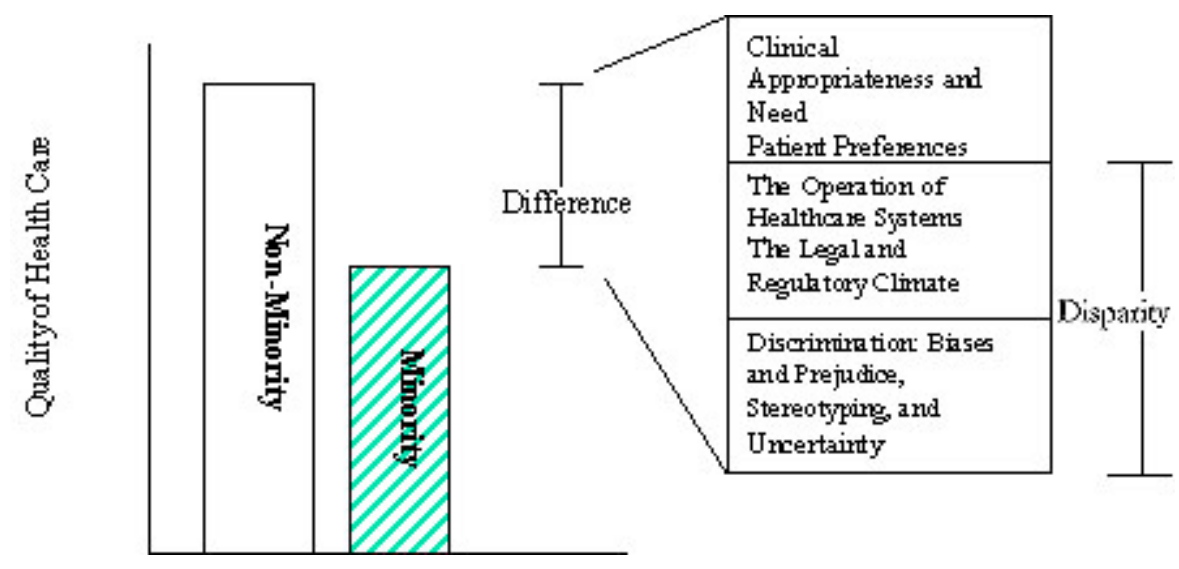

Figure 5-1. Differences, disparities, and discrimination: Populations with equal access to health care.

Source: Smedley, I., Stith, B.D., Nelson, A.R. Institute of Medicine (U.S.). Unequal Treatment Committee on Understanding and Eliminating Racial and Ethnic Disparities in Health Care. National Academies Press, 2003. Reprinted with permission.

unintended consequences of the operation of the health care system and the legal and regulatory climate or it may be as a result of discriminatory bias or stereotyping (Fig. 5-1).

The discrepancy between blacks and whites with respect to PKT is multifaceted and is influenced by several factors that dictate how the PKT and conventional transplant process unfolds. It is disparities like those outlined in this research and others that prompted Congress to request an Institute of Medicine (IOM) study committee to assess differences in the kinds and quality of health care received by minorities when compared to non-minorities. While the study committee did not focus specifically on PKT or conventional kidney transplantation they did define disparities in health care as racial or ethnic differences in the quality of health care that are not due to access related factors or clinical needs, preferences, and appropriateness of intervention. The committee's analysis was focused at two levels: 1) the operation of health care systems and the legal and regulatory climate in which health systems function; and 2) discrimination at the individual, patient-provider level. 
Discrimination, as the committee uses the term, refers to differences in care that result from biases, prejudices, stereotyping, and uncertainty in clinical communication and decisionmaking (Smedley, Stith, \& Nelson, 2003). While discrimination at the patient level can never be dismissed, a type of discrimination that is more subtle is institutional discrimination. This refers to policies, procedures, and practices that may appear to be neutral, but the end result is uneven access by group membership to resources, status and power (IOM, 2003). It is the perspective of this research that the systemic failures of the health care system and lesions in the health policy, legal and regulatory climate that contribute significantly to the disparities in the allocation of PKT between blacks and whites.

Despite the lower percentages of black patients in this study receiving PKT and the lower percentages of PKT reflected in other research, Weng and Mange (2003) indicated that patients who underwent the PKT evaluation process overwhelmingly (75\%) indicated a desire to receive a transplant before initiation of maintenance dialysis. This was consistent with their stated negative impressions of their anticipated quality of life on dialysis. However, despite the preferences expressed by these patients and the commencement of the transplant evaluation process preemptively, the disparity in PKTs for blacks still exists. Although this disparity may stem from the complexity of modern medical care, which requires access to physicians, proper diagnosis of renal disease, comprehension by the patient of their disease, and referral to a nephrologists and then to a transplant center (Weng \& Mange, 2003) PKT remains a preferred option that requires that the transplant evaluation occur preemptively.

Correcting any inequities in PKT will no doubt require substantial effort on the part of those who care for patients with kidney disease, and especially those who refer them for 
transplant evaluation (Kasiske et al., 2002). One critical element in addressing PKT is to ensure black patients are referred to nephrologists and transplant centers relatively early in the course of progressive renal disease (Kausz, et al., 2001), because late referral to nephrology care, when the need for renal replacement therapy is imminent, is associated with increased mortality rates (Stack, 2003) and decreased rates of PKT and conventional transplants. Individuals can only be evaluated with sufficient lead-time to undergo PKT if patients as well as physicians are educated about the detection and recognition of asymptomatic renal disease and the benefits of early referral to a nephrologist. This will require more extensive education about utilizing valid formulae to provide an age, gender and race adjusted estimated GFR. (Mange \& Weir, 2003). Nephrologists should discuss the advantages of PKT with the patients and advocate that these individuals present to a transplant center for evaluation, even at the expense of diminishing the nephrologists' dialysis population and subsequent reimbursement for providing dialysis care (Ayanian, et al., 1999).

As this research points out, individuals with primary causes of ESRD, such as diabetes and hypertension were significantly less likely to receive a PKT. Diabetes and especially hypertension tend to affect blacks at higher rates and promote ESRD. The rate at which blacks develop CKD and ultimately reach ESRD will most certainly not change unless the medical community can educate blacks and other minorities on how to take charge of their health by adopting healthy lifestyles that are likely to ameliorate the tendency toward obesity, diabetes, and hypertension. As the results of this research reflects, for blacks diabetes is the underlying cause of ESRD for $22 \%$ of all PKT transplant recipients and $34 \%$ of all conventional transplant recipients. Hypertension was the primary cause of ESRD for 
$19 \%$ of all PKT and $32 \%$ of all black conventional kidney transplant recipients. These results support other research that indicated that diabetes and/or hypertension was the primary cause of ESRD in 70\% of all new ESRD cases (Young and Kew, 2005). Diabetes is nearly $50 \%$ more prevalent in blacks than in whites and the pattern of hypertension among blacks in the U.S. is unique and remains the leading cause of ESRD for all ages. Odds ratios from this research show that those without diabetes or hypertension as the primary cause of their ESRD are 2 and 3 times, respectively, higher odds of getting a PKT. Based on these primary causes of ESRD the likelihood of receiving a PKT for blacks is diminished significantly. In order to change the downstream possibilities of increasing the rates at which blacks receive PKT the cormobid conditions that are shown to diminish the likelihood of receiving a PKT must be addressed. This research says that independent of these disease states, being black also affects whether an ESRD patient will receive a PKT or not.

\section{DISPARITIES IN PKT, UNOS, AND THE HEALTH POLICY IMPLICATIONS}

The UNOS waiting list was designed as a just and equitable system through which a limited number of organs are allocated to the thousands of Americans in need of a transplant. People on the waiting list continue to trust the system because of the belief that everyone on the list has an equal opportunity to receive a kidney and that allocation is blind to practices and policies that have the potential to be exploited. Policies that allow or permit the manipulation of the waiting list in any way are not only unethical but challenge the integrity of the UNOS system (Zink, et al., 2005). Preemptive transplantation when someone has not spent a significant amount of time on the waiting list is either a direct contradiction of the clearly articulated UNOS policy that one accumulates points for time on the waiting list or a 
practice that is carried out under the guise of a policy variance, alternative allocation or distribution exception, or what is identified as the committee-sponsored alternative system provisions of the UNOS policies. Such options within the organ allocation policies are in theory designed for the purpose of increasing organ availability and/or organ quality, and allowing the latitude to subjectively reduce or address an inequity in organ allocation/distribution unique to the local area, and/or examining a policy variation intended to benefit the allocation/distribution system overall.

As this research has shown, virtually all the preemptive kidney recipients experience a lapse time of one day from their first ESRD service and transplantation. While this does not automatically mean that these individuals spent less time on the waiting list than all other potential recipients, it does lend itself to the possibility that significant numbers of predialysis patients are being placed on the waiting list earlier and more often in certain regions of the country than in others.

The UNOS organ allocation protocols have numerous shortcomings and as a result of the demand for a scarce resource continues to grow those waiting become desperate and look for ways to circumvent policies that govern the waiting list. It could be argued, this is what is being done in order to get the population for preemptive kidney transplants. By subjectively placing patients on the waiting list at various stages of renal failure the process of organ allocation will remain inequitable. In a system with such limited resources, an advantage obtained by one person directly causes the disadvantage of another (Zink, et al., 2005).

UNOS and the medical community have agreed that the most effective and ethical way to allocate organs is through a balance of the principles of equity and utility. According 
to the principle of equity as outlined by Zink, et al., (2005) once placed on the UNOS waiting list, every member of the list should have an equal chance of receiving a much needed organ. Allocation of organs through the principles of utility should result in the prioritization of organs to the best candidates in the most need (Zink et al., 2005). Striking the balance between the two principles can never be done through the subjective application of the UNOS policies currently in effect. Practices such as solicitation for organs, directed donation, multiple listing or preemptive kidney transplantation were never intended to allow people to gain an unfair advantage. Regardless of the intent of such practices each of them has inherent within it the potential for abuse.

In 2003, UNOS modified the allocation algorithm to eliminate points for HLA matching but continues to allow for local variances based on the concept of acceptable mismatches that at least theoretically, preserve the benefits of matching while offering more equitable allocation (Takemoto, et al., 2000). In light of the increasing recognition of the influence of non-immunologic factors on long time survival, this is yet another opportunity for the subjective abuse of the organ allocation decision making process. Given all the subjective latitude built into the allocation policies it may be time to formulate a completely new paradigm for organ allocation.

\section{FUTURE RESEARCH CONSIDERATIONS}

The continued examination of UNOS policies is an absolute necessity in ongoing efforts to ensure the just and equitable allocation of kidneys and for a system to avoid the exploitation by those who are forced to resort to desperate measures during desperate times. The growing gap between the demand for lifesaving organs and their availability as reflected 
during this study leaves thousands waiting for an organ and thousands more to die before a kidney can be allocated to them. Hence the compelling need to improve the system of organ procurement and allocation Socioeconomic status is routinely identified in the literature as having an impact on whether someone gets kidney transplant or not (Young \& Kew, 2005). Although a significant number of poorer members of the majority population are clearly present in all parts of the United States, the number of blacks with incomes below the federal poverty level is fourfold greater than the number of whites at this level (Young \& Kew, 2005). As a result, blacks are much more likely to be dependent on public assistance programs such as Medicare and Medicaid for health insurance and medication coverage. As Kasiske, et al. (2002) pointed out in their study the primary source of payment was the strongest correlate of PKT. Kasiske's research supports (Table 4-15) that patients who had Medicare as the primary payer or as a secondary payer were much less likely to receive preemptive transplants.

Kasiske's study (2002) as does this study conceded the point that it was probable Medicare may be a surrogate for other socioeconomic factors. As the authors go on to point out that even though Medicare may eventually cover the cost of transplantation, the significant expenses that may be incurred before qualifying for Medicare may be prohibitive for may patients who could otherwise be candidates for PKT. In another study Kasiske, et al. (1998) points out those patients who have suboptimal insurance coverage may be more likely to fail to keep initial appointments with the transplant center, due to concerns about cost and payment. According to Kasiske et al. (1998) others have found that race and socioeconomic factors influence health care utilization even when there is adequate insurance coverage (Gornick, et al., 1996). As pointed out in this research, when insurance coverage is equal 
(Table 4-15) race and perhaps unidentified socioeconomic factors and institutional systems still lead to differences in PKT rates. Overcoming socioeconomic barriers to health care is not simply a matter of insurance coverage. Given that Medicare covers the cost of transplantation, preemptive and conventional, it is possible that removing the pre-transplant disincentives by expanding Medicare coverage to make PKT more accessible to those limited to Medicare coverage that blacks may experience increased PKT rates. Further evaluation of the impact of Medicare on the ESRD population specifically relating to receipt of PKT needs to be undertaken.

The benefits of PKT are well documented in the literature; however, the benefits of PKT are not shared equally among transplant recipients. This research validates the perceptions of the inequities in the allocation of both preemptive and conventional cadaver kidney transplants. This validation of that perception of inequity threatens the very foundation upon which our system of altruistic organ donation is built. In a global society that prides itself on a high level of sensitivity and equality, there is an ethical and moral imperative to address the continuing racial/ethnic disparities in PKT and the many factors that are potentially underlying this disparity. Given the rising demand for kidney transplantation within a setting of scarce resources, the economic and ethical dimensions of transplant medicine are of increasing interest and importance to patients, providers and payers. Continued research in this area focusing on health policy and practice adaptations will assist in uncovering ways to maximize use of PKT in an ethical and cost-effective manner that ultimately results in reduced cost to the ESRD program and the prolonging and improvement in the quality of many lives. A specific example would be primary care policy 
changes mandating the screening of hypertensive blacks for declining kidney function so that priority consideration could be given for PKT. 


\section{LIST OF REFERENCES}

Agodoa L. Lessons from chronic renal diseases in African American Americans: Treatment implications. Ethn Dis 2003;13(Suppl 2):118-24.

Alexander GC, Sehgal AR. Barriers to cadaveric renal transplantation among blacks, women, and the poor. JAMA 1998;280:1148-52.

Asderakis, A., Augustine, T., Dyer, P., Short, C., Campbell, B., Parrott, N.R., Johnson, R.W., Pre-emptive kidney transplantation: The attractive alternative. Nephrol Dial Transplant 1998; 13:1799-1803.

Ayanian, J, Clearly, P, Weissman, J, Epstein, A. The effects of patients' preferences on racial differences in access to renal transplantation. N Engl J Med 1999; 341:1661-9.

Ayanian J.Z, Clearly P.D., Keogh J.H., et al. Physician's beliefs about racial differences in referral for renal transplantation. Am J Kidney Dis 2004;43(2):350-7.

Ayanian J.Z., Cleary P.D., Weissman J.S., et al. The effect of patients' preferences on racial differences in access to renal transplantation. New Engl J Med 1999;341:1661-9.

Barnett AH, Kaserman D.L. Comment on "The Shortage in Market-Inalienable Human Organs": Faulty Analysis of a Failed Policy Amer J of Econ and Soc April 2000; 59(2):33549.

Beatty P.G., Mori M., Milford E., Impact of racial genetic polymorphism on the probability of finding an HLA-matched donor. Transplantation 1995; 60:778-83.

Burt V.I., Whelton P., Roccalla E.J., et al. Prevalence of hypertension in the U.S. adult population: Results from the Third National Health and Nutrition Examination Survey 1988-1991. Hypertension 1995;25:305-13.

Callender C., Hall L.E., Yeager C.L., Barber J.B., Dunston G.M., Pinn-Wiggins V.W., Organ donation and blacks. New Engl J Med 1991;325(6): 442-4.

Callender C.O., Organ donation in the black population: Where do we go from here? Transplant Proc 1987;19: Suppl 2:36-40.

Cecka J.M. The UNOS Scientific Renal Transplant Registry. In: Cecka J.M., Terasaki P.I., editors. Clinical transplants 1998. Los Angeles (CA): UCLA Tissue Typing Laboratory; 1999. p.1-16.

Coresh J., Wei G.K., McQuillian G., et al. Prevalence of high blood pressure and elevated serum creatinine level in the United States: Findings from the Third National Health and 
Nutrition Examination Survey (1988-1994). Arch Intern Med 2001;161:1207-16.

Cosimi A.B. The Donor and the Donor Nephrectomy. In: Morris P.J., ed. Kidney

Transplantation: Principles and Practice, $4^{\text {th }}$ ed. Philadelphia, PA: Saunders, 1994:56-70.

Crook E.D., Harris J., Oliver B., et al., End-stage renal disease owing to diabetic nephropathy in Mississippi: an examination of factors influencing renal survival in a population prone to late referral. J Invest Med 2001;49(3):284-91.

Delmonico F.L., Milford E.L., Goguen J., et al. A novel United Network for Organ Sharing: Region kidney allocation plan improves transplant access for minority candidates.

Transplantation 1999;68:1875-9.

Eggers P.W. Effect of transplantation on the Medicare End-Stage Renal Disease Program. N Engl J Med 1988;318:223-9.

Eggers P.W. Racial differences in access to kidney transplantation. Health Care Financing Rev 1995; 17:2:89-102.

Epstein A.M., Ayanian J.Z., Keogh J.H., Noonan S.J., Armistead N., Cleary P.D., Weissman, J.S., David-Kasdan J.A., Carlson D., Fuller J., Marsh D., Conti, R.M.. Racial disparities in access to renal transplantation clinically appropriate or due to underuse or overuse. N Engl J Med 2000;343:1537-44.

Feldman H.I., Roth D.A., Fazio I., et al. National kidney allograft sharing: A decision analysis. Transplantation 1997;64:80-8.

Foster C.E., Philosophe B., Schweitzer E.J., A decade of experience with renal transplantation in African-Americans. Ann Surg 2002; 236:794-805.

Furth S.L., Garg P., Neu A.M., Hwang W., Fivush B.A. Racial differences in access to the Kidney Transplant Waiting List for Children and Adolescents with ESRD. Transplantation, 2000; S237.

Gadegbeku C., Freeman M., Lawrence, A. Racial disparities in renal replacement therapy. JAMA Supp 2002;94:8:45S-54S.

Garg P.P., Diener-West M., Powe N.R. Reducing racial disparities in transplant activation: Whom should we target? Am J Kidney Dis 2001;37(5):921-31.

Geiger H.J. Race and health care: An American dilemma. New Engl J Med 1996;335:815-6.

Gill, J.S., Tonelli, M., Johnson, N., Pereira, B.J., Why do pre-emptive kidney transplant recipients have an allograft survival advantage? Transplantation 2004; 78:873-9.

Gornick, M.E., Eggers, P.W., Reilly T.W. Effects of race and income on mortality and use of services among Medicare beneficiaries. N Engl J Med 1996;335:791-9. 
Hall W.D., Ferrario C.M., Moore M.A., Hall J.E., Flack J.M., Cooper W., Simmons J.D., Egan B.M., Lackland D.T., Perry M. Jr, Roccella E.J. Hypertension-related morbidity and mortality in the southeastern United States. Am J Med Sci 1997 Apr;313(4):195-209.

Harris M.I. Diabetes in America: Epidemiology and scope of the problem. Diabetes Care. 1998; Feb;24(2):412.

Heaf J.G., Lokkegaard H.U., Madsen M. Initial survival advantage of peritoneal dialysis relative to hemodialysis. Nephrol Dial Transplant 2002;11:116-25.

Health Care Financing Administration. End Stage Renal Disease Annual Report to Congress. Washington, D.C., 1981. Government Printing Office, 1982. (HCFA publication no. 8202144).

Health Care Financing Administration. End Stage Renal Disease Research Report: 1984. Washington, D.C., 1986. (HCFA Publication no. 03221).

Held P.J., Kahan B.D., Hunsicker L.G., et al. The impact of HLA mismatches on the survival of first cadaver kidney transplants. New Engl J Med 1994;331:765-70.

Institute of Medicine. Unequal Treatment: Confronting Racial and Ethnic Disparities in Health Care, Washington, D.C. 2003.

Jacobs C., Brunner F.P., Chantler C., Donckerwolcke R.A. Combined report on regular dialysis and transplantation in Europe. Proc Eur Dial Transplant Assoc, 1977.

Kasiske, B., London, W., Ellison, M., Race and socioeconomic factors influencing early placement on the kidney transplant waiting list. J Am Soc Nephrol 1998; 9:2142-7.

Kasiske, B., Snyder, J.J., Matas, A.J., Ellison, M.D., Gill, J.S., Kausz, A.T. Preemptive kidney transplantation: The advantage and the advantaged. Am Soc Nephrol 2002; 13:135864.

Kasiske B.L., Cohen D., Lucey M.R., Neylan J.F. Payment for immunosuppression after organ transplantation. American Society of Transplantation. JAMA 2000;283: 2445-50.

Kasiske B.L., London W., Ellison M. Race and socioeconomic factors influencing early placement on the kidney transplant waiting list. J Am Soc Nephrol 1998;9:2142-7.

Katz S.M., Kerman R.H., Golden D., Grevel J., Camel S., Lewis R.M., Van Buren C.T., Kahan B.D. Preemptive transplantation-An analysis of benefits and hazards in 85 cases. Transplantation 1991; 51:351-5,

Kausz A.T., Obrador G.T., Arora P., Ruthazer R., Levey A.S., Pereira B.J. Late initiation of dialysis among women and ethnic minorities in the United States. J Am Soc Nephrol 2000; $11: 2351-7$. 
King H., Aubert R.E., Herman W.H. Global burden of diabetes, 1995-2025: prevalence, numerical estimates, and projections. Diabetes Care. 1998 Sep;21(9):1414-31.

Klag M.J., Stamler J., Brancat F., et al. End-stage renal disease in African-American and white men: 16-year MRFIT findings. JAMA 1997;277(16):1293-8.

Krop J.S., Coresh J., Chamblers L.E., et al. A community-based study of explanatory factors for the excess risk for early renal function decline in blacks vs. whites with diabetes: The atherosclerosis risk in communities study. Arch Intern Med 1999;159(5):1777-83.

Lazda A. The impact of HLA frequency differences in races on the access to optimally HLA-matched cadaver renal transplants. Transplantation 1992;53:352-7.

Lazda V.A., Blaesing M.E. Is allocation of kidneys on basis of HLA match equitable in multiracial populations? Transplant Proc 1989;21:1415-6.

Mange, K.C., Weir, M.R., Pre-emptive renal transplantation: Why not? Am J Transplantation 2003; 3:1336-40.

Meier-Kriesche H., Port F.K., Ojo, A.O., Rudich S.M., Hanson J.A., Cibrik D.M., Leichtman A.B., Kaplan B. Effect of waiting time on renal transplant outcome. Kidney International 2000; 58:1311-7.

Migliori R.J., Simmons R.L., Payne W.D., Ascher N.L. Renal transplantation done safely without prior chronic dialysis therapy. Transplantation, 1987;43(1):51-5.

Norman D.J., Ellison M.D., Breen T.J., Davies D.B., Daily O.P. Cadaver kidney allocation in the United States: A critical analysis of the point system. Transplant Proc 1995; 27:800.

Norris K.C., Agodoa L.Y. Race and kidney disease: The scope of the problem. JAMA Supp 2002; 94:8: 2S-6S.

Norris K.C., Agodoa L.Y. Unraveling the racial disparities associated with kidney disease. Kidney Int 2005 Sep;68(3):914-24.

Nzerue C.M., Demissachew H., Tucker J.K. Race and kidney disease: Role of social and environmental factors. JAMA Supp 2002; 94:8:28S-38S.

Owen W.F., Jr., Chertow G.M., Lazarus J.M., Lowrie E.G. Dose of hemodialysis and survival: Differences by race and sex. JAMA 1998;280:1764-8.

Papalois, V.E., Moss, A., Gillingham, K.J., Sutherland, D.E., Matas, A.J., Humar, A. Preemptive transplants for patients with renal failure: An argument against waiting until dialysis. Transplantation; 2000; 70:625-31. 
Park J.K., Joh .TH., Ebner F.F. Tyrosine hydroxylase is expressed by neocortical neurons after transplantation proceedings of the National Academy of Sciences, 1986 - National Acad Sciences Proc Nat Acad Sci 1986; 83: 7495-8.

Pichette V., Querin S., Desmeules M., Ethier J., Copleston P. Renal function recovery in endstage renal disease. Am J Kidney Dis 1993;22:398-402.

Powe N.R., Boulware L.E. The Uneven Distribution of Kidney Transplants: Getting at the root causes and improving care. Am J of Kidney Dis 2002; 40:861-3.

Qualheim R.E., Rostand S.G., Kirk K.A., et al. Changing patterns of end stage renal disease due to hypertension. Am J Kidney Dis 1991;18:336-43.

Relman A.S., Rennie D. Treatment of end-stage renal disease: Free but not equal. N Engl J Med 1980;303:996-8.

Roake, J.A., Cahill, A.P., Gray, C.M., Gray, D., Morris, P.J., Preemptive Cadaveric Renal Transplantation-Clinical Outcome. Transplantation 1996;62:1411-6.

Roubicek C., Brunet P., Huiart L., et al. Timing of nephrology referral: Influence on mortality and morbidity. AM J Kidney Dis. 2000; 36:35-41.

Rozon-Solomon M., Burrows L. The relative failure of the African American community to provide organs for transplantation. The Mount Sinai Journal of Medicine, 1999;66(4):273-6.

Scantlebury V., Gjertson D., Eliasziw M., et al. Effect of HLA mismatch in African Americans. Transplantation 1998;65:586-8.

Smedley, I., Stith, B.D., Nelson, A.R. Institute of Medicine (U.S.). Unequal Treatment Committee on Understanding and Eliminating Racial and Ethnic Disparities in Health Care. National Academies Press, 2003.

Soucie J.M., Neylan J.F., McClellan W. Race and sex differences in the identification of candidates for renal transplantation. Am J Kidney Dis 1992;19:414-9.

Stack A.G., Molony D.A., Rahman N.S., Dosekun A. Impact of dialysis modality on survival of new ESRD patients with congestive heart failure in the United States. Kidney International, 2003;64:1071-9.

Szczech L., Lazar I. Projecting the United States ESRD population: Issues regarding treatment of patients with ESRD. Kidney Int 2004;66:S3-S7.

Takemoto S., Terasaki P.I., Gjertson D.W., et al. Equitable allocation of HLA-compatible kidneys for local pools and for minorities. New Engl J Med 1994;331:760-4. 
Takemoto S.K., Terasaki P.I., et al. Twelve years' experience with national sharing of HLA matched cadaveric kidneys for transplantation. New Engl J Med 2000;343(15): 1078-84.

Tankersley M.R., Gaston R.S., Curtis J.J., et al. The living donor process in kidney transplantation: Influence of race and co-morbidity. Transplant Proc 1997;29:3722-3.

Tegzes A.M., Fidler V.J., Voort-Beelen V.D. Successful outcome of second transplant and its implications. Transplantation 1987; 43:240-4.

Thamer M., Hwang W., Fink N.E., et al. US nephrologists' attitudes towards renal transplantation: Results from a national survey. Transplantation 2001;71(2):281-8.

United Network for Organ Sharing. UNOS 1999 annual report of the US Scientific Registry of Transplant Recipients and the Organ Procurement and Transplantation Network. Transplant data: 1994-1998. Richmond (VA): United Network for Organ Sharing, 1999.

US Renal Data System. Chapter IX. The Economic Cost of ESRD and Medicare Spending for Alternative Modalities of Treatment. In: USRDS 1996 Annual Data Report. Bethesda, MD: National Institutes of Health, National Institute of Diabetes, Digestive and Kidney Diseases, 1997.

US Renal Data System. Excerpts from the USRDS 1999 Annual data report. Am J Kidney Dis 1999;34 (Suppl 1):S1-176.

US Renal Data System. USRDS 2001 Annual Data Report. Bethesda (MD): National Institutes of Health, National Institute of Diabetes and Digestive and Kidney Diseases, 2001.

US Renal Data System. USRDS 2002 Annual Data Report. Bethesda (MD): National Institutes of Health, National Institute of Diabetes and Digestive and Kidney Diseases, 2002.

US Renal Data System. USRDS 2003 Annual data report: Atlas of end-stage renal disease in the United States. Bethesda (MD): National Institutes of Health, National Institute of Diabetes and Digestive and Kidney Diseases, 2003.

US Renal Data System. USRDS 2005 Annual data report: atlas of end-stage renal disease in the United States. Bethesda (MD): National Institutes of Health, National Institute of Diabetes and Digestive and Kidney Diseases, 2005.

United States Renal Data System Researcher's Guide to the USRDS Database. National Institutes of Health, National Institute of Diabetes and Digestive and Kidney Diseases, Bethesda, MD, 2005. Required notice: "The data reported here [i.e., in this dissertation] have been supplied by the United States Renal Data System (USRDS). The interpretation 
and reporting of these data are the responsibility of the author(s) and in no way should be seen as an official policy or interpretation of the U.S. government."

Warnock D.G. Low renin hypertension in the next millennium. Semin Nephrol 2000;20:40-6.

Weng, F.L., Mange, K.C., A comparison of persons who present for pre-emptive and nonpre-emptive kidney transplantation. Am J of Kidney Diseases 2003; 42:1050-7.

Weng, F.L., Mange, K.C., Joffe, M.M., Feldman, H.I., Rates of completion of the medical evaluation for renal transplantation. Am. J of Kidney Diseases 2005; 46:734-45.

Winkelmayer WC, Owen W, Glynn RJ, et al. Preventive health care measures before and after start of renal replacement therapy. J Gen Intern Med 2002 Aug;17(8):588-95.

Wolf R.A., Ashby A.V., Milford E.I., et al. Comparison of mortality in all patients on dialysis, patients on dialysis awaiting transplantation, and recipients of first cadaveric transplant. New Engl J Med 1999;341:725-32.

Young C.J., Gaston R.S.. Renal transplantation in black Americans. N Eng J Med 2000; $343: 1545-52$.

Young, C.J., Kew C. Health disparities in transplantation: focus on the complexity and challenge of renal transplantation in African Americans. Med Clin N Am 2005; 89:1003-31.

Zink, S., Wertieb, S., Catalano, J., Marwin, V. Examining the potential exploitation of UNOS policies. Am J of Bioethics 2005; 5(4):6-10.

2001 Annual Report of the U.S. Organ Procurement and Transplantation Network and the Scientific Registry of Transplant Recipients: Transplant Data 1993-2002. Department of Health and Human Services, Health Resources and Services Administration, Office of Special Programs, Division of Transplantation, Rockville, MD; United Network for Organ Sharing, Richmond, VA; University Renal Research and Education Association, Ann Arbor, MI.

2006 Annual Report of the U.S. Organ Procurement and Transplantation Network and the Scientific Registry of Transplant Recipients: Transplant Data 1996-2005. Health Resources and Services Administration, Healthcare Systems Bureau, Division of Transplantation, Rockville, MD. 


\section{VITA}

Kennard D. Brown was born in Hayti, Missouri, in 1956. He received his B.A. in Psychology and Criminal Justice from The University of Memphis. Mr. Brown attended the Cecil C. Humphrey's School of Law at The University of Memphis and received his J.D. in 1995. Upon receiving his license to practice law in the State of Tennessee, he opened a private law practice focused on employment and health law. In August of 2001, he also received an M.A. in Public Administration from The University of Memphis. Mr. Brown is a member of Phi Kappa Phi, the national Public Administration Honor Society. He will receive his Ph.D. in Health Policy from The University of Tennessee Health Science Center in May 2008.

Mr. Brown began his career with The University of Tennessee Health Science Center approximately five years ago in the Office of the General Counsel. From there he became the Director of Affirmative Action. While still serving as the Director of that office, which is now titled the Office of Equity and Diversity, he also assumed responsibilities as Director of Employee Relations, which includes staff training and development. Mr. Brown currently serves as Executive Vice Chancellor and Chief of Staff for the Health Science Center Campus and principally functions as the chief administrative officer, with oversight for dayto-day operations of the campus. 